\title{
Theoretical Studies of Molecular Structures, Infrared Spectra, NBO and NLO Properties of Some Novel 5-arylazo-6-hydroxy-4-phenyl-3-cyano-2-pyridone Dyes
}

\begin{abstract}
A. $\operatorname{ESME}^{a, *}$ AND S.G. SAGDINC ${ }^{b}$
${ }^{a}$ Department of Elementary Science Education, Kocaeli University, 41380, Umuttepe, Kocaeli, Turkey

${ }^{b}$ Department of Physics, Science and Art Faculty, Kocaeli University, 41380, Umuttepe, Kocaeli, Turkey

(Received February 18, 2016; in final form November 5, 2016)

The optimized geometrical structures, infrared spectra, molecular electrostatic potential, natural bond orbital and nonlinear optical properties of 5-phenylazo-6-hydroxy-4-phenyl-3-cyano-2-pyridoine (1) and 5-(4-bromophenylazo)-6-hydroxy-4-phenyl-3-cyano-2-pyridoine (2) dyes with a detailed study on the azo-hydrazone tautomerism in the ground state have been investigated by density functional theory using B3LYP functional with $6-31 \mathrm{G}(\mathrm{d}, \mathrm{p})$ basis set. Vibrational modes are assigned with the help of vibrational energy distribution analysis program. Highest occupied molecular orbital and lowest unoccupied molecular orbital energies of the (1) and (2) compounds with azo and hydrazone forms were calculated with the same method and basis set. Molecular parameters like global hardness $(\eta)$, global softness $(\sigma)$ and electronegativity $(\chi)$ were calculated with the results obtained from the highest occupied and lowest unoccupied molecular orbital energies. Nonlinear optical parameters (mean polarizability $(\langle\alpha\rangle)$, the anisotropy of the polarizability $(\langle\Delta \alpha\rangle)$ and the mean first-order hyperpolarizability $(\langle\beta\rangle))$ of the title compounds were investigated theoretically. The atomic charges, electronic exchange interaction, and charge delocalization of the molecules have been studied by natural bond orbital analysis.
\end{abstract}

DOI: $10.12693 /$ APhysPolA.130.1273

PACS/topics: 31.15.E-, 33.20.Ea, 31.50.Bc, 42.65.-k

\section{Introduction}

Azo dyes containing at least a chromophore azo group $(-\mathrm{N}=\mathrm{N}-)$ are an important class of synthetic organic colorants which are extensively used in the dyestuffs industry and also, more recently, in the field of non-linear optics [1]. There has been growing interest in the nonlinear optical (NLO) properties of azo materials for their large nonlinear refraction which are interesting for the application in optical storage capacity, optical-limiting and optical switching application [2]. Besides, the arylazo colorants belonging to the azo dyes class are a very important class of colorants. The importance of arylazo pyridone dyes containing pyridone rings have increased due to the use of polyester and nylon as the main synthetic fibers. Azo pyridone dyes have largely replaced yellow disperse dyes based on pyrazolones due to their bright hues and suitability for the dyeing of polyester fabrics [3, 4]. Pyridone disperse yellow dyes, such as C.I. Disperse Yellows 114, 119, and 211, are used for dyeing polyester fabrics $[5,6]$.

Pyridone derivatives are relatively recent heterocyclic intermediates for the preparation of arylazo dyes and several investigations on substituted arylazo pyridone dyes have been carried out and reviewed [7-9]. The physicochemical properties of arylazo pyridone dyes are closely related to their azo and hydrazone tautomerism which occurs in azo dyes bearing groups with labile proton conjugated with azo linkage. It has been concluded that the

\footnotetext{
* corresponding author; e-mail: asli.esme@kocaeli.edu.tr
}

equilibrium between the two tautomers is influenced by the structure of the compounds [10].

In the previous publication, a series of some novel arylazo pyridone dyes have been synthesized (Fig. 1) by Alimmari et al. [11]. The structures of 5-phenylazo-6-hydroxy-4-phenyl-3-cyano-2-pyridoine (1) and 5-(4-bromophenylazo)-6-hydroxy-4-phenyl-3-cyano2-pyridoine (2) dyes were experimentally confirmed by UV-vis, the Fourier transform infrared (FT-IR), ${ }^{1} \mathrm{H}-$ NMR and ${ }^{13} \mathrm{C}-\mathrm{NMR}$ spectroscopic techniques and elemental analysis. Literature survey reveals that so far there is no complete theoretical calculation on the (1) and (2) molecules published which has motivated us to undertake a detailed quantum mechanical analysis for understanding the structural, electronic and NLO properties, natural bond orbital (NBO) analysis and vibrational studies for the azo and hydrazone forms of some arylazo pyridone dyes, (1) and (2), using (density functional theory, DFT) B3LYP/6-31G(d,p) method. Therefore, the aim of this study is to fully determine the molecular structures, FT-IR spectra and assignments, frontier molecular orbital energies, molecular electrostatic potential and nonlinear optical properties of (1) and (2) dyes. Detailed interpretations of the vibrational spectra of (1) and (2) compounds have been made based on the calculated percentage potential energy distribution (PED).

\section{Computational procedure}

All calculations of the (1) and (2) molecules have been performed using the Gaussian 09 Rev. A 11.4 [12] software package and the output files were visualized by means of the GaussView Rev. 5.0.9 [13] software. 
(1) compound (a)

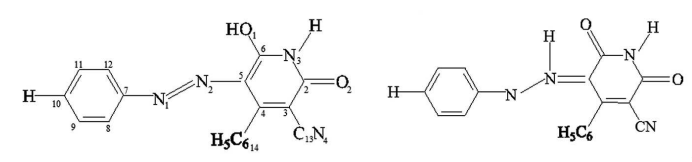

(2) compound (b)

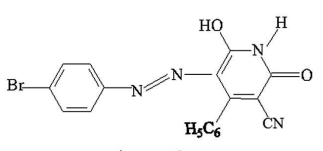

Azo form

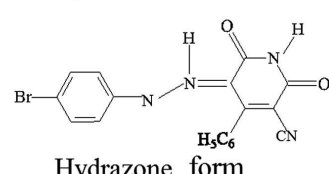

Hydrazone form
Fig. 1. Azo-hydrazo tautomerism in studied arylazo pyridine dyes.

The full geometrical optimization of the title compounds in the gas phase were carried out using the B3LYP/6$31 \mathrm{G}(\mathrm{d}, \mathrm{p})$ method. The DFT calculations were performed using Becke's three-parameter hybrid functional [14] with the Lee-Yang-Parr correlation functional [15], a combination that gives rise to the well-known B3LYP method. The optimized structure parameters (bond lengths and dihedral angles), vibrational frequencies, IR and Raman intensities of title compounds were calculated by using B3LYP/6-31G(d,p) method. The theoretical vibrational modes of (1) and (2) compounds using percentage potential energy distribution (PED) have been done with the VEDA4 program written by Jamroz [16]. At the optimized structures of the molecules no imaginary frequency modes were obtained, providing that a true minimum on the potential energy surface was found. The vibrational frequencies obtained from the B3LYP calculations have been scaled by a factor of 0.9608 [17], which is a typical correction factor for B3LYP frequencies [18]. Highest occupied molecular orbital (HOMO) and lowest unoccupied molecular orbital (LUMO) calculations were made at the same level of theory. The natural bond orbital (NBO) calculations were performed using NBO 3.1 program [19] as implemented in the Gaussian 09 [12] package at the $\mathrm{B} 3 \mathrm{LYP} / 6-31 \mathrm{G}(\mathrm{d}, \mathrm{p})$ level in order to understand various second order interactions between the filled orbitals of one subsystem and vacant orbitals of another subsystem, which is a measure of the intermolecular delocalization or hyper conjugation.

In the context of the $\mathrm{HF}$ theorem, the $E_{\mathrm{HOMO}}$ and $E_{\text {LUMO }}$ is used to approximate the ionization potential (I) and electron affinity (A) given by Koopmans' theorem [20], respectively. Although no formal proof of this theorem exists within DFT, its validity is generally accepted. DFT has shown to be successful in providing insights into the chemical reactivity, in terms of molecular parameters such as global hardness $(\eta)$, global softness $(\sigma)$, and electronegativity $(\chi)$.

$I$ and $A$ are related to

$$
I=-E_{\mathrm{HOMO}}, \quad A=-E_{\mathrm{LUMO}} \text {. }
$$

The global hardness $(\eta)$ is a measure of the resistance of an atom to charge transfer [21] and it can be calcu- lated as

$$
\eta=\left(\frac{I-A}{2}\right)=-\frac{1}{2}\left(E_{\mathrm{HOMO}}-E_{\mathrm{LUMO}}\right) .
$$

The global softness $(\sigma)$ describes the capacity of an atom or a group of atoms to receive electrons [21] and is equal to reciprocal of global hardness

$$
\sigma=\frac{1}{\eta}=-\frac{2}{\left(E_{\mathrm{HOMO}}-E_{\mathrm{LUMO}}\right)} .
$$

Electronegativity $(\chi)$ is a measure of the power of an atom or a group of atoms to attract electrons towards itself [22] and can be calculated from HOMO-LUMO as

$$
\chi=\left(\frac{I+A}{2}\right)=-\frac{1}{2}\left(E_{\mathrm{HOMO}}+E_{\mathrm{LUMO}}\right) .
$$

Polarizabilities were calculated at the same level of theory using the standard GAUSSIAN-09W keyword "Polar" [23]. This keyword means that the polarizabilities were obtained analytically rather than by numerical differentiation.

The energy of an uncharged molecule under a weak, general electric field can be expressed by Buckingham type expansion [24-26]:

$$
\begin{aligned}
E & =E_{0}-\mu_{i} F_{i}-(1 / 2) \alpha_{i j} F_{i} F_{j}-(1 / 6) \beta_{i j k} F_{i} F_{j} F_{k} \\
& -(1 / 24) \gamma_{i j k l} F_{i} F_{j} F_{k} F_{l}-\ldots
\end{aligned}
$$

where $E$ is the energy of a molecule under the electric field $F, E_{0}$ is the unperturbed energy of a free molecule, $F_{i}$ is the vector component of the electric field in the $i$-th direction, and $\mu_{i}, \alpha_{i j}, \beta_{i j k}, \gamma_{i j k l}$ are the dipole moment, linear polarizability, first-order hyperpolarizability, and second-order hyperpolarizability, respectively. Here, each subscript of $i, j, k$, and $l$ denotes the indices of the Cartesian axes $x, y, z$, and a repeated subscript means a summation over the Cartesian indices $x, y, z$. The ground state dipole moment $(\mu)$, the mean polarizability $\langle\alpha\rangle$, the anisotropy of the polarizability $\langle\Delta \alpha\rangle$ and the mean first-order hyperpolarizability $(\beta)$, using the $x, y, z$ components they are defined as [27, 28]:

$$
\begin{aligned}
& \mu=\left(\mu_{x}^{2}+\mu_{y}^{2}+\mu_{z}^{2}\right)^{1 / 2} \\
& \langle\alpha\rangle=\frac{\alpha_{x x}+\alpha_{y y}+\alpha_{z z}}{3} \\
& \langle\Delta \alpha\rangle=\left\{\frac { 1 } { 2 } \left[\left(\alpha_{x x}-\alpha_{y y}\right)^{2}+\left(\alpha_{y y}-\alpha_{z z}\right)^{2}\right.\right. \\
& \left.\left.\quad+\left(\alpha_{z z}-\alpha_{x x}\right)^{2}+6\left(\alpha_{x y}^{2}+\alpha_{x z}^{2}+\alpha_{y z}^{2}\right)\right]\right\}^{1 / 2} \\
& \beta=\left[\left(\beta_{x x x}+\beta_{x y y}+\beta_{x z z}\right)^{2}+\left(\beta_{y y y}+\beta_{y z z}+\beta_{y x x}\right)^{2}\right. \\
& \left.\quad+\left(\beta_{z z z}+\beta_{z x x}+\beta_{z y y}\right)^{2}\right]^{1 / 2}
\end{aligned}
$$

The mean polarizability and mean first-order hyperpolarizability tensors $\left(\alpha_{x x} \alpha_{x y}, \alpha_{y y}, \alpha_{x z}, \alpha_{y z}, \alpha_{z z}\right.$, and $\beta_{x x x}, \beta_{x x y}, \beta_{x y y}, \beta_{y y y}, \beta_{x x z}, \beta_{x y z}, \beta_{y y z}, \beta_{x z z}$, $\left.\beta_{y z z}, \beta_{z z z}\right)$ can be obtained by frequency job output file of GAUSSIAN-09W [12]. Since the values of the mean polarizabilities $(\alpha)$ and mean first-order hyperpolarizability $(\beta)$ of GAUSSIAN-09W output are reported in atomic units (a.u.), the calculated values have been 
converted into electrostatic units (esu) $(\alpha$ : 1 a.u. $=$ $0.1482 \times 10^{-24} \mathrm{esu} ; \beta$ : 1 a.u. $\left.=8.6393 \times 10^{-33} \mathrm{esu}\right)[29]$.

\section{Results and discussion}

\subsection{Electronic properties}

The total energies and relative total energies of azo and hydrazone tautomers of (1) and (2) molecules calculated at B3LYP/6-31G(d,p) and B3LYP/aug-cc-pVDZ levels of theory are given in Table I. The total energy has also influence on the stability of a molecule. The total energies of (1) molecule have been calculated using B3LYP/6-31G(d,p) and B3LYP/aug-cc-pVDZ levels as -1062.5796 and -1062.5629 a.u. for hydrazone forms (3633.6815 and -3636.1184 a.u. for hydrazone forms of (2) molecule) and -1062.5744 and -1062.5491 a.u. for azo forms (-3633.6770 and -3636.1031 a.u. for azo forms of (2) molecule), respectively. These results indicate that the hydrazone forms of (1) and (2) compounds are more stable than azo forms in gas phase.

TABLE I

Total energy (in a.u.), the relative total energies (in kcal $/ \mathrm{mol}$ ), $E_{\text {Hомо }}, E_{\mathrm{Lumo}}, \Delta E_{\mathrm{LumO}}$-Homo, ionization potential $(I)$, electron affinity $(A)$, molecular hardness $(\eta)$, electronegativity $(\chi)$ (in $\mathrm{eV}$ ) and molecular softness $(\sigma)\left[\mathrm{eV}^{-1}\right]$ values of $(1)$ and $(2)$ tautomers obtained by B3LYP/6-31G(d,p) and B3LYP/aug-cc-pVDZ levels.

\begin{tabular}{c|c|c|c|c}
\hline \hline & \multicolumn{2}{|c|}{$(1)$} & \multicolumn{2}{c}{$(2)$} \\
\cline { 2 - 5 } & $\begin{array}{c}\text { Azo } \\
\text { form }\end{array}$ & $\begin{array}{c}\text { Hydrazone } \\
\text { form }\end{array}$ & $\begin{array}{c}\text { Azo } \\
\text { form }\end{array}$ & $\begin{array}{c}\text { Hydrazone } \\
\text { form }\end{array}$ \\
\hline total energy $^{a}$ & -1062.5744 & -1062.5796 & -3633.6770 & -3633.6815 \\
total energy $^{b}$ & -1062.5491 & -1062.5629 & -3636.1031 & -3636.1184 \\
$\Delta E^{a}$ & 3.26 & 0.00 & 2.82 & 0.0000 \\
$\Delta E^{b}$ & 8.66 & 0.00 & 9.60 & 0.0000 \\
$E_{\text {HOMO }}$ & -5.987 & -6.055 & -6.064 & -6.135 \\
$E_{\mathrm{LUMO}}$ & -3.349 & -2.609 & -3.495 & -2.781 \\
$\Delta E_{\mathrm{LUMO}}-\mathrm{HOMO}$ & 2.6374 & 3.4466 & 2.5682 & 3.3533 \\
$I$ & 5.9873 & 6.0559 & 6.0641 & 6.1351 \\
$A$ & 3.3499 & 2.6093 & 3.4959 & 2.7818 \\
$\eta$ & 1.3187 & 1.7233 & 1.2841 & 1.6767 \\
$\sigma$ & 0.7583 & 0.5803 & 0.7788 & 0.5964 \\
$\chi$ & 4.6686 & 4.3326 & 4.7800 & 4.4585 \\
\hline
\end{tabular}

$a$ Total energies [a.u.] and the relative total energies [kcal $/ \mathrm{mol}]$ obtained by B3LYP/6-31G(d,p) level.

$b$ Total energies [a.u.] and the relative total energies [kcal $/ \mathrm{mol}]$ obtained by B3LYP/aug-cc-pVDZ level.

$E_{\mathrm{HOMO}}$ and $E_{\mathrm{LUMO}}$ refer to the highest occupied molecular orbital and lowest unoccupied molecular orbital energies, respectively. The HOMO (ability to donate an electron) implies the outermost orbital filled by electrons and is directly related to the ionization potential while the LUMO (ability to obtain an electron) can be thought as the first empty innermost orbital unfilled by electron and is directly related to the electron affinity. The HOMO and LUMO are called as the frontier molecule orbitals (FMOs). The HOMO-LUMO 3D orbital pictures computed at the B3LYP/6-31G (d,p) level for the title compounds are given in Fig. 2. The positive and negative phases are represented in red and green colour, respectively. As seen from Fig. 2, the LUMOs of both azo and hydrazone tautomers of (1) and (2) molecules are largely delocalized almost over the whole molecular moiety but the HOMOs of both tautomers are mainly delocalized on the whole of tautomeric structures except phenyl rings.

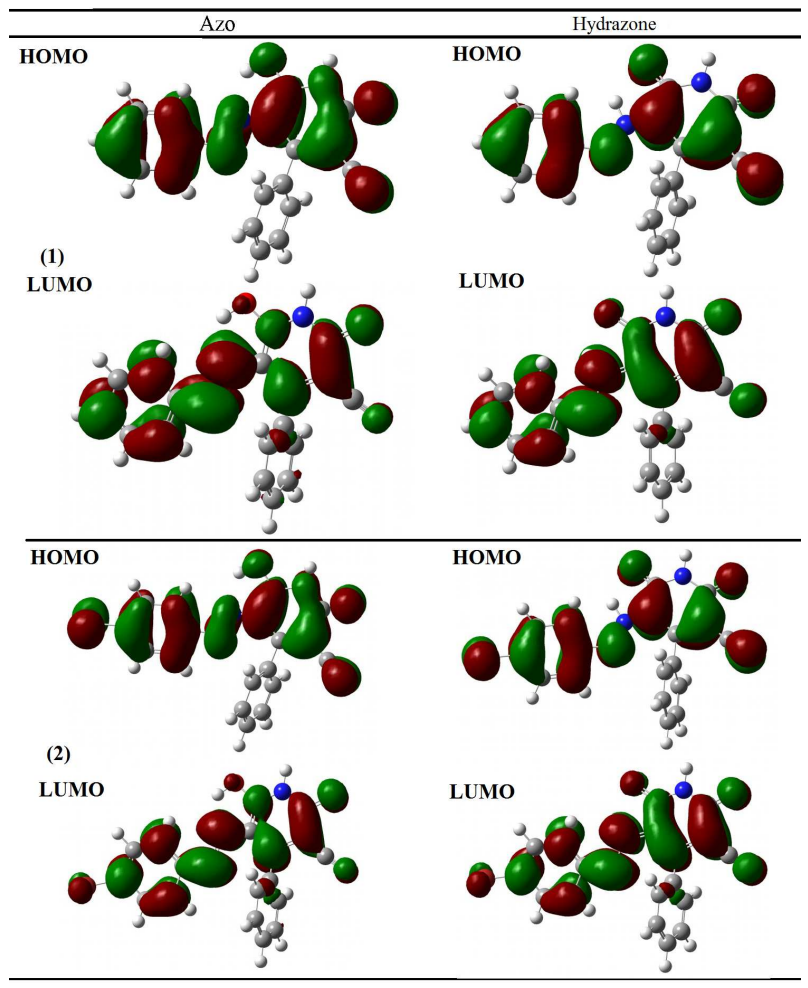

Fig. 2. The 3D plots frontier orbital energies for the azo and hydrazone tautomers of (1) and (2) compounds obtained by B3LYP/6-31G(d,p) level.

The calculated values for the $E_{\mathrm{HOMO}}$ and $E_{\mathrm{LUMO}}$ and the frontier molecular orbital energy gap $\left(\Delta E_{\mathrm{LUMO}}-\mathrm{HOMO}\right)$ with $\mathrm{B} 3 \mathrm{LYP} / 6-31 \mathrm{G}(\mathrm{d}, \mathrm{p})$ method are given in Table I. There are the formed energy gaps between the HOMO and LUMO. The frontier orbital gap helps to characterize the chemical reactivity and kinetic stability of the molecule. Meanwhile, a molecular with a small frontier orbital gap is more polarizable and is generally associated with a high chemical reactivity, low kinetic stability and is also termed as soft molecule $[30,31] . \quad E_{\mathrm{HOMO}}$ and $E_{\mathrm{LUMO}}$ of (1) have been calculated using B3LYP/6-31G(d,p) level as $-6.0559 \mathrm{eV}$ and $-2.6093 \mathrm{eV}(-6.1351 \mathrm{eV}$ and $-2.7818 \mathrm{eV}$ of $(2))$ for hydrazone form and $-5.9873 \mathrm{eV}$ and $-3.3499 \mathrm{eV}(-6.0641 \mathrm{eV}$ and $-3.4959 \mathrm{eV}$ of $(2))$ for azo form, respectively. The calculated values of the frontier orbital energy gap for (1) and (2) are 3.4466 and $3.3533 \mathrm{eV}$ for hydrazone form and 2.6374 and $2.5682 \mathrm{eV}$ for azo form, respectively (Table I).

The calculations of the frontier molecular orbital energy gaps for the (1) and (2) compounds using the B3LYP/6-31G(d,p) method indicate that the $\Delta E_{\mathrm{LUMO}-\mathrm{HOMO}}$ values between the LUMO and HOMO 
orbital energies obtained for the hydrazone forms of (1) and (2) compounds, respectively (3.4466 and $3.3533 \mathrm{eV}$ ) are relatively higher than their values in the azo forms (2.6374 and $2.5682 \mathrm{eV}$ ). This indicates that the electron transfer from the HOMO orbital to the LUMO orbital is easier in the azo form for both compounds. Therefore, the hydrazone forms of (1) and (2) compounds are more stable than azo form of (1) and (2) compounds.

\subsection{Molecular geometry}

The arylazo pyridone dyes (1) and (2) having the same pyridone skeleton investigated in this work may exist in two tautomeric forms (Fig. 1). Depending on the tautomers, two types of intramolecular hydrogen bonds are observed in arylazo pyridone dyes: $\mathrm{O}-\mathrm{H} \cdots \mathrm{N}$ in azo and $\mathrm{N}-\mathrm{H} \cdots \mathrm{O}$ in hydrazone tautomers. The optimized molecular structures for the azo and hydrazone tautomers of the aryazo pyridine dyes (1) and (2) using the B3LYP/6-
$31 \mathrm{G}(\mathrm{d}, \mathrm{p})$ method are shown in Fig. 3a,b. Many researchers have studied the azo-hydrazone forms of arylazo pyridone dyes [32-34]. Table II composes the optimized structural parameters such as bond lengths and dihedral angles obtained only by geometrical optimization - since no experimental geometrical data are available in the literature - for the azo and hydrazone tautomers of (1) and (2) molecules by performing B3LYP with $6-31 \mathrm{G}(\mathrm{d}, \mathrm{p})$ basis set. DFT calculations for the azohydrazone tautomers of dye (1) and the experimental structures of the arylazo pyridone dyes (1) and (2) have been reported by Alimmari et al. [11]. But the theoretical and experimental geometric data have not been given in that paper. Therefore we have compared the calculated structural parameters of the arylazo pyridone dyes (1) and (2) with experimentally available parent compound 2-pyridone from the X-ray study [35] and M06$2 \mathrm{X} / 6-31+\mathrm{G}(\mathrm{d}, \mathrm{p})$ values obtained by Dostanić et al. [32].

TABLE II

Experimental and calculated bond lengths and dihedral angles at M06-2X/(6-31+G(d,p)) [32] and B3LYP/6-31G(d,p) methods for tautomeric forms of the (1) and (2) compounds.

\begin{tabular}{|c|c|c|c|c|c|c|c|c|c|}
\hline \multirow{5}{*}{$\begin{array}{c}\text { Bond } \\
\text { lengths }\end{array}$} & \multirow{5}{*}{ X-ray $[35]$} & \multirow{2}{*}{\multicolumn{4}{|c|}{$\frac{\text { M06-2X } /(6-31+\mathrm{G}(\mathrm{d}, \mathrm{p}))[32]}{\text { Substituents }(\mathrm{R})}$}} & \multirow{2}{*}{\multicolumn{4}{|c|}{$\begin{array}{c}\text { B3LYP /6-31G }(\mathrm{d}, \mathrm{p}) \\
\text { Substituents }(\mathrm{R})\end{array}$}} \\
\hline & & & & & & & & & \\
\hline & & \multicolumn{2}{|r|}{$\mathrm{H}$} & \multicolumn{2}{|r|}{$\mathrm{Br}$} & \multicolumn{2}{|r|}{$\mathrm{H}$} & \multicolumn{2}{|c|}{$\mathrm{Br}$} \\
\hline & & \multicolumn{2}{|r|}{ (1) } & \multicolumn{2}{|r|}{ (2) } & \multicolumn{2}{|c|}{ (1) } & \multicolumn{2}{|c|}{ (2) } \\
\hline & & $\overline{\mathrm{Azo}}$ & Hydrazo & Azo & Hydrazo & $\mathrm{Azo}$ & Hydrazo & $\mathrm{Azo}$ & Hydrazo \\
\hline $\mathrm{R}-\mathrm{C} 10$ & - & 1.085 & 1.087 & 1.881 & 1.882 & 1.086 & 1.085 & 1.907 & 1.903 \\
\hline $\mathrm{C} 7-\mathrm{N} 1$ & $1.39(2)$ & 1.416 & 1.408 & 1.414 & 1.406 & 1.413 & 1.397 & 1.411 & 1.394 \\
\hline $\mathrm{N} 1-\mathrm{N} 2$ & $1.31(2)$ & 1.263 & 1.292 & 1.264 & 1.294 & 1.264 & 1.282 & 1.265 & 1.284 \\
\hline $\mathrm{N} 2-\mathrm{C} 5$ & $1.32(1)$ & 1.376 & 1.318 & 1.375 & 1.315 & 1.394 & 1.359 & 1.392 & 1.358 \\
\hline $\mathrm{C} 5-\mathrm{C} 6$ & $1.48(2)$ & 1.410 & 1.472 & 1.410 & 1.474 & 1.404 & 1.469 & 1.405 & 1.470 \\
\hline $\mathrm{C} 6-\mathrm{O} 1$ & $1.19(2)$ & 1.300 & 1.231 & 1.301 & 1.230 & 1.326 & 1.236 & 1.326 & 1.236 \\
\hline $\mathrm{C} 5-\mathrm{C} 4$ & $1.45(2)$ & - & - & - & - & 1.435 & 1.426 & 1.436 & 1.426 \\
\hline N3-C6 & $1.40(1)$ & - & - & - & - & 1.342 & 1.373 & 1.342 & 1.373 \\
\hline N3-C2 & $1.33(2)$ & - & - & - & - & 1.419 & 1.404 & 1.420 & 1.404 \\
\hline $\mathrm{C} 3-\mathrm{C} 4$ & $1.37(2)$ & - & - & - & - & 1.391 & 1.386 & 1.391 & 1.386 \\
\hline C3-C13 & $1.45(2)$ & - & - & - & - & 1.429 & 1.426 & 1.429 & 1.426 \\
\hline C4-C14 & $1.52(2)$ & - & - & - & - & 1.493 & 1.494 & 1.493 & 1.494 \\
\hline $\mathrm{C} 2-\mathrm{O} 2$ & $1.23(1)$ & - & - & - & - & 1.218 & 1.219 & 1.218 & 1.219 \\
\hline $\mathrm{C} 3-\mathrm{C} 2$ & $1.47(2)$ & - & - & - & - & 1.464 & 1.476 & 1.464 & 1.477 \\
\hline $\mathrm{O}-\mathrm{H} \cdots \mathrm{N}$ & - & - & - & - & - & 1.968 & - & 1.976 & - \\
\hline $\mathrm{N}-\mathrm{H} \cdots \mathrm{O}$ & $1.61(6)$ & - & - & - & - & - & 1.982 & - & 1.977 \\
\hline $\begin{array}{c}\text { corr. } \\
\text { coefficient }\end{array}$ & & & & & & 0.79 & 0.95 & 0.79 & 0.95 \\
\hline \multicolumn{10}{|c|}{ Dihedral angles } \\
\hline C7-N1-N2-C5 & 179.36 & & & & & 179.30 & 177.34 & 179.29 & 177.37 \\
\hline $\mathrm{N} 1-\mathrm{N} 2-\mathrm{C} 5-\mathrm{C} 6$ & & & & & & 171.20 & 174.79 & 171.77 & 174.83 \\
\hline $\mathrm{N} 1-\mathrm{N} 2-\mathrm{C} 5-\mathrm{C} 4$ & 179.56 & & & & & -7.32 & -3.54 & -6.78 & -3.53 \\
\hline $\mathrm{N} 2-\mathrm{C} 5-\mathrm{C} 6-\mathrm{O} 1$ & & & & & & 1.62 & 2.72 & 1.60 & 2.73 \\
\hline
\end{tabular}

Firstly, by analyzing the dihedral angles around $\mathrm{N}-\mathrm{N}$ moiety, all atoms of around N1-N2 of (1) and (2) compounds form nearly a planar molecule according to DFT calculation (Table II), as also supported by reported X-ray analysis result [35] with the torsion angle of $179.36^{\circ}(\mathrm{C}-\mathrm{N}-\mathrm{N}-\mathrm{C})$. From the values of N1-N2-C5-C4 dihedral angle calculated with B3LYP/6-31G(d,p) level in Table II, it can be seen that the arylazo pyridone ring is found $-7.32^{\circ}$ and $-3.54^{\circ}$ (in the azo and hydrazone structures, respectively) for (1) compound and $-6.78^{\circ}$ and $-3.53^{\circ}$ out of plane (in the azo and hydrazone structures, respectively) for (2) compound. An im- 
(1) compound (a)
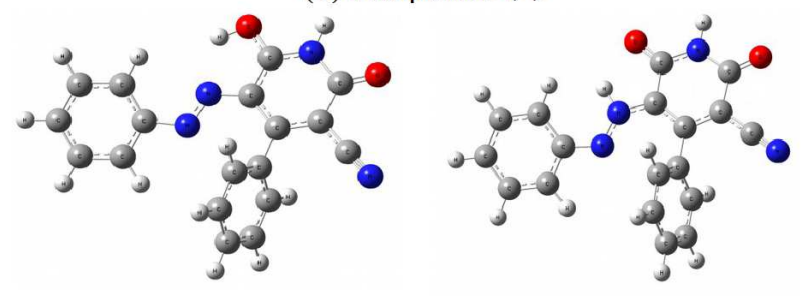

(2) compound (b)

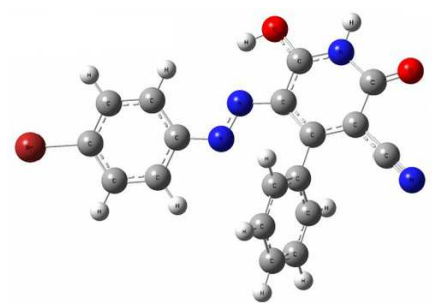

Azo form

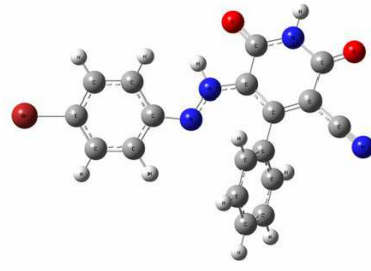

Hydrazone form
Fig. 3. (a) and (b) Tautomeric equilibria between azo and hydrazone forms, respectively, of the (1) and (2) compounds, (c) and (d) optimized structures between azo and hydrazone forms, respectively, of (1) and (2) compounds obtained using B3LYP/6-31G(d,p) level.

portant feature of the molecules is the strong intramolecular hydrogen bond formed between the hydrogen $\mathrm{H}(\mathrm{N} 2)$ and the 6-carbonyl group. The predicted $\mathrm{O}-\mathrm{H} \cdot \cdots \mathrm{N}$ (azo) and $\mathrm{N}-\mathrm{H}$. . O (hydrazone) distances for the compounds (1) and (2), respectively, are 1.968 and $1.976 \AA$ for theazo tautomer, and $1.982 \AA$ and $1.977 \AA$ for the hydrazone tautomer (with B3LYP/6-31G(d,p)). These distances are significantly smaller than the summation of the Van der Waals radii $(2.6 \AA)$, just confirming the presence of a very strong hydrogen interaction in these compounds $[6,37]$. The $\mathrm{N}_{2} \ldots \mathrm{O}$ distance is approximately $2.60 \AA$ for (1) and (2) compounds, which is smaller than those intramolecular hydrogen bond, $\mathrm{N}^{-} \cdot . \mathrm{O}=\mathrm{C}$, in molecules that do not present electronic configuration (the N. . O distance varies from 2.996 to $3.210 \AA$ [38]).

The calculated $\mathrm{N}-\mathrm{N}$ and $\mathrm{C}-\mathrm{N}$ bond lengths of these compounds are also presented in Table II. As can be seen from Table II, from the crystalline structure described for parent compound 2-pyridone, the $\mathrm{N}-\mathrm{N}$ bond length was 1.31(2) $\AA$ [35]. The calculated $\mathrm{N}-\mathrm{N}$ bond distances were $1.264 \AA$ and $1.265 \AA$ for azo tautomer, whereas the $\mathrm{N}-\mathrm{N}$ bond distance for the hydrazone isomer was 1.282 and $1.284 \AA$ (at $\mathrm{R}-\mathrm{H}$ and $\mathrm{RBr}$ substituents, respectively). The N1-N2 bond lengths calculated for azo form of (1) and (2) compounds are longer than average $\mathrm{N}=\mathrm{N}$ distance for structural fragment $\mathrm{C}_{\mathrm{ar}}-\mathrm{N}=\mathrm{N}-\mathrm{C}_{\mathrm{ar}}$ [39], but still not long enough to be considered as $\mathrm{N}_{\mathrm{sp} 2}-\mathrm{N}_{\mathrm{sp} 2}$ standard single bond length $(1.401 \AA)$. This suggests a considerable electron delocalization on the azo linkage. In hydrazone form the N1-N2 bond length values are shorter than $\mathrm{N}_{\mathrm{sp} 2}-\mathrm{N}_{\mathrm{sp} 2}$ single bond, which suggests a partially double bond character of it. The shortening of the hydrazone bond is related to the conjugation of $\mathrm{N} 1-\mathrm{N} 2$ bond with pyridone or benzene ring.
The calculated $\mathrm{C}-\mathrm{N}$ bond lengths for these arylazo pyridone dyes compared with those corresponding to data reported in the literature [32]. These results from Table II clearly show that the bond lengths C7-N1 (1.413 and 1.397 of (1) compound and 1.411 and 1.394 of (2) compound for azo and hydrazone form, respectively) between benzene ring and azo bond fall between single $\mathrm{C}-\mathrm{N}$ (1.431) and double $\mathrm{C}=\mathrm{N}$ (1.279) bond, but have more single character in all forms. As shown in Table II, the calculated values with B3LYP/6-31G(d,p) level correspond well to those within the literature [32].

The N2-C5 bond lengths for (1) and (2) compounds have single-double character, which indicates resonance character between $\mathrm{N} 1-\mathrm{N} 2$ bond and the aromatic ring. This bond has more single character in azo form (1.394 for (1) and 1.392 for (2)), and more double character in hydrazone form (1.359 for (1) and 1.358 for (2)).

While the optimized $\mathrm{C}-\mathrm{C}$ bonds of the rings for (1) and (2) compounds lie in the range of 1.391-1.493 Afor azo form and 1.386-1.494 Afor hydrazone form, the experimental values observed in the range of $1.37(2)-1.52(2) \AA$.

The $\mathrm{C}=\mathrm{O}$ distances of both (1) and (2) were found $1.326 \AA$ for azo form and $1.236 \AA$ for hydrazone form. The short $\mathrm{C}=\mathrm{O}$ distance $(1.236 \AA)$ for hydrazone form was nearer the $\mathrm{C}=\mathrm{O}$ distance of $1.23 \AA$ for the carbonyl group than the $\mathrm{C}-\mathrm{O}$ distance $(1.35 \AA)$ found in phenols [40].

The data given in Table II obviously showed that the magnitude of the bond length was affected by substituent type. Structural analysis also revealed that the length of the bond that connects substituent $\mathrm{R}$ and benzene ring, $\mathrm{R}-\mathrm{C} 10$, is almost the same in azo $(1.085 \AA, 1.086 \AA$ for (1) and $1.881 \AA, 1.907 \AA$ for (2), Ref. [32] and B3LYP /6$31 \mathrm{G}(\mathrm{d}, \mathrm{p})$, respectively) and hydrazone (1.087 $\AA, 1.085 \AA$ for (1) and 1.882, $1.903 \AA$ for (2), Ref. [32] and B3LYP /6$31 \mathrm{G}(\mathrm{d}, \mathrm{p})$, respectively) forms compared with those corresponding to data reported in the literature [32].

For comparison with the experimental parameters, the calculated correlation $\left(R^{2}\right)$ coefficients obtained with B3LYP/6-31G(d,p) level for the azo and hydrazone tautomers of the aryazo pyridine dyes (1) and (2) wereshown in Fig. 4. We can see in Table II that the bond lengths

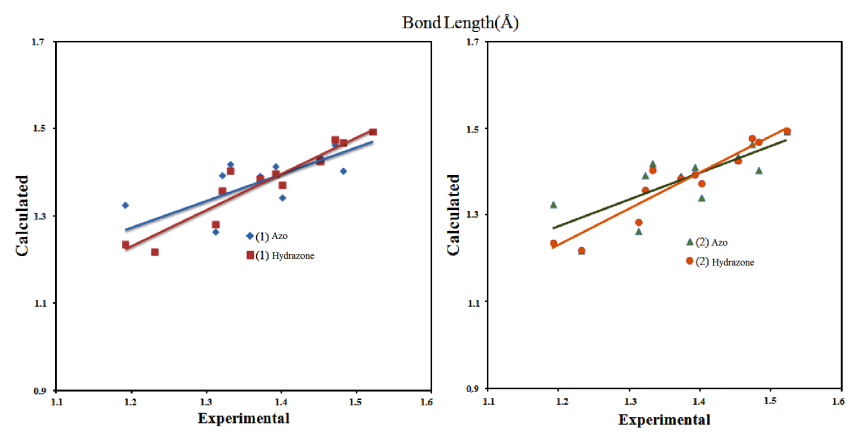

Fig. 4. Correlation graphics of experimental [35] and theoretical (with $6-31 \mathrm{G}(\mathrm{d}, \mathrm{p})$ ) bond lengths of the (1) and (2) compounds. 
calculated by using the B3LYP methods with 6-31 G(d,p) basis set for the azo and hydrazone form of (1) and (2) compounds correlate fairly with experimental data $\left(R^{2}\right.$ is both 0.79 for azo isomers and 0.95 for hydrazone isomers). According to B3LYP/6-31G(d,p) method, bond lengths of (1) and (2) compounds in hydrazone form give satisfactory result (linear correlation coefficients are $R 2=0.95)$. For azo forms, the correlation coefficients obtained at B3LYP $/ 6-31 \mathrm{G}(\mathrm{d}, \mathrm{p})$ are both 0.79 . The reason for this is that the azo tautomers are lower stability than the hydrazone forms thus are much lower percentage.

\subsection{Global reactivity descriptors}

Development of new chemical reactivity descriptors has gained significant momentum due to their applications in various areas of chemistry, biology, rational drug design and computer-aided toxicity prediction [41]. The understanding of chemical reactivity and selectivity of the molecular systems has been effectively handled by the conceptual DFT [42]. Global hardness $(\eta)$, global softness $(\sigma)$ and electronegativity $(\chi)$ are global reactivity descriptors, highly successful in predicting global chemical reactivity trends.

Associated within the framework of self-consistency function (SCF), MO theory, the ionization potential (I) and electron affinity (A) can be expressed through $E_{\mathrm{HOMO}}$ and $E_{\mathrm{LUMO}}$ orbital energies as $I=-E_{\mathrm{HOMO}}$ and $A=-E_{\text {Lumo. }}$. The obtained values of $I$ and $A$ were considered with most popularly used formulae for the computation of global hardness, global softness and electronegativity. Various reactivity descriptors as global hardness $(\eta)$, global softness $(\sigma)$ and electronegativity $(\chi)$ were evaluated using the standard working Eqs. (1)-(4) and these values calculated with B3LYP/6-31 G(d,p) level were listed in Table II. The global hardness $(\eta)$ and global softness $(\sigma)$ correspond to the gap between the $E_{\text {HOMO }}$ and $E_{\text {LUMO orbital energies and have been as- }}$ sociated with the stability of chemical system. A soft molecule has a small energy gap and is more reactive than a hard one because it could easily offer electrons to an acceptor. The calculations with B3LYP/6-31G(d,p) method show that the global hardness $(\eta)$ values of hydrazone tautomers for both molecules are greater than azo forms, and the global softness values of hydrazone tautomers are smaller than azo forms. This means that azo tautomers for both molecules have the largest potential chemical resistance to change the number of electrons among the other tautomers. Besides, these results indicate that hydrazone tautomers for both molecules are more stable than others in the gas phase.

\subsection{Total electron density, molecular electrostatic potential, and electrostatic potential analyses}

Molecular electrostatic potential (MEP), $V(r)$, at a given point $r(x, y, z)$ in the vicinity of a molecule, is defined in terms of the interaction energy between the electrical charge generated from the molecule's electrons and nuclei and a positive test charge (a proton) located at $r$. For the system studied the $V(r)$ values were calculated as described previously using equation [43]:

$$
V(r)=\sum_{A} \frac{Z_{A}}{\left(R_{A}-r\right)}-\int \frac{\rho\left(r^{\prime}\right)}{\left(r^{\prime}-r\right)} \mathrm{d} r^{\prime},
$$

where $Z_{A}$ is the charge of nucleus $A$, located at $R_{A}$, $\rho\left(r^{\prime}\right)$ is the electronic density function of the molecule, and $r^{\prime}$ is the dummy integration variable.

$\mathrm{MEP}$ is typically visualized through mapping its values onto the surface reflecting the molecules boundaries. The different values of the MEP at the surface are represented by different colors; red, electron rich, partially negative charge; blue, electron deficient, partially positive charge; light blue, slightly electron deficient region; yellow, slightly electron rich region; and green, neutral. Potential increases in the order red $<$ orange $<$ yellow $<$ green $<$ blue. The molecular electrostatic potential is related to the electronic density and a very useful descriptor for determining sites for electrophilic attack and nucleophilic reactivities as well as hydrogen-bonding interactions [43, 44].

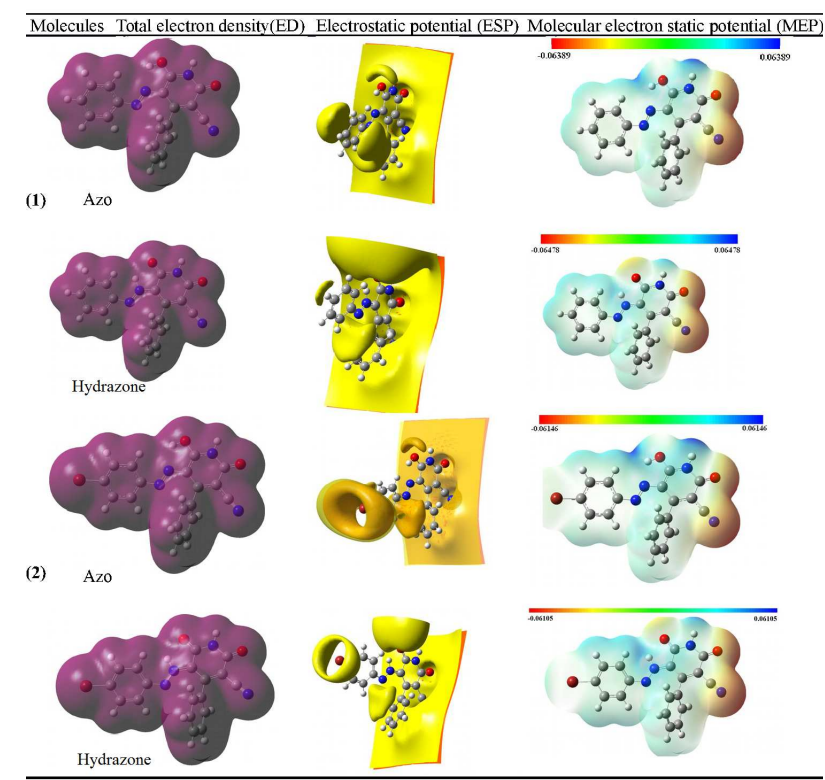

Fig. 5. The 3D plots of total ED, ESP, and MEP of (1) and (2) tautomers calculated at B3LYP/ 6-31G(d,p) level.

In the present study, the 3D plots of electrostatic potential (ESP), total electron density (ED) and MEP of (1) and (2) tautomers at B3LYP/6-31G(d,p) level are illustrated in Fig. 5. The ED plots for azo and hydrazone tautomers of (1) and (2) molecules show a uniform distribution. The MEP maps of (1) and (2) tautomers are shown in Fig. 5, where as electrophilic attack is presented by negative (red) regions, nucleophilic reactivity is shown by positive (blue) regions of MEP map of (1) and (2) tautomers. As seen from Fig. 5, the red regions are mainly localized on 3-cyano $(\mathrm{C} \equiv \mathrm{N})$ and 2-pyridines group, showing most favorable site for electrophilic attack. On the 
other hand, when focused on positive regions of the electrostatic potential, we found that the hydrogen atoms of 2-pyridones ring are surrounded by blue color, indicating that these sites are probably involved in nucleophilic processes.

It can be seen from the ESP figure (Fig. 5) that the negative ESP is localized more over the $\mathrm{Br}$ atom and 2pyridines ring and is reflected as a yellowish blob and the positive ESP is localized on the rest of the molecules.

\subsection{NLO properties}

In order to investigate the relationship among molecular structure and NLO properties, the dipole moments $(\mu)$, the polarizabilities $(\alpha)$, the anisotropy of the polarizabilities $(\langle\Delta \alpha\rangle)$ and the first-order hyperpolarizabilities $(\beta)$ for azo and hydrazone forms of (1) and (2) molecules were calculated using the B3LYP/6$31 \mathrm{G}(\mathrm{d}, \mathrm{p})$ basis set, based on the finite-field approach. The dipole moment $(\mu)$ in a molecule is an important property, which is mainly used to study the intermolecular interactions involving the non-bonded type dipoledipole interactions, because the higher the dipole moment, the stronger the intermolecular interactions will be [45]. The dipole moments of (1) and (2) tautomers obtained using DFT calculations are summarized in Table III. The calculated dipole moments for hydrazone

TABLE III

Dipole moments $\mu$ (D), polarizabilities $\langle\alpha\rangle$ (in a.u. and esu), the anisotropic of the polarizabilities $\langle\Delta \alpha\rangle$ (in a.u.) and the first-order hyperpolarizabilities (in a.u. and esu) values obtained using B3LYP/6$31 \mathrm{G}(\mathrm{d}, \mathrm{p})$ method for azo and hydrazone tautomers of $(1)$ and (2) compounds.

\begin{tabular}{c|c|c|c|c}
\hline \hline \multirow{2}{*}{ form } & \multicolumn{2}{|c|}{$(1)$} & \multicolumn{2}{c}{$(2)$} \\
\cline { 2 - 5 } & azo & hydrazone & azo & hydrazone \\
\hline$\mu[\mathrm{D}]$ & 8.4724 & 9.5352 & 6.6296 & 7.6384 \\
$\langle\alpha\rangle[$ a.u.] & 253.65 & 278.08 & 285.53 & 316.07 \\
$\langle\alpha\rangle \times 10^{-24}$ [esu] & 37.59 & 41.21 & 42.32 & 46.84 \\
$\langle\Delta \alpha\rangle$ [a.u.] & 238.56 & 313.38 & 306.20 & 397.14 \\
$\beta$ [a.u.] & 1260.28 & 730.20 & 888.09 & 4575.34 \\
$\beta_{\text {tot }} \times 10^{-30}[\mathrm{esu}]$ & 10.89 & 6.31 & 7.67 & 39.53 \\
$\beta_{\text {tot }} / \beta_{\text {urea }}$ & 56 & 32 & 39 & 203
\end{tabular}

forms (9.5352 and 7.6384 D) of the (1) and (2) compounds, respectively, have higher values than azo forms $(8.4724$ and $6.6296 \mathrm{D})$. The polarizabilities $(\alpha)$, the anisotropy of the polarizabilities $(\langle\Delta \alpha\rangle)$ and the firstorder hyperpolarizabilities $(\beta)$ for azo and hydrazone forms of (1) and (2) molecules using B3LYP/6-31G(d,p) level are listed in Table III. Softness and polarizability are assumed to be related: "a soft species is also more polarizable." Thus, a hard (soft) species is known to correspond to a low (high) value of the polarizability as well as a small (large) size [46]. As seen in Table III, hydrazone forms of (1) and (2) compounds are softer and more polarizable than azo forms of these compounds.

It is well known that the higher values of first-order hyperpolarizability are important for more active NLO properties. Urea is one of the prototypical molecules used in the study of the NLO properties of molecular systems. Therefore it was used frequently as a threshold value for comparative purposes. Theoretically, the first-order hyperpolarizabilities for $\mathrm{NH}$ forms of the (1) and (2) compounds are of 32 and 203 times magnitude of urea (the $\beta$ of urea is $0.1947 \times 10^{-30} \mathrm{esu}$ ), respectively. We conclude that the title compounds are attractive objects for future studies of NLO properties.

\subsection{Natural bond orbital analysis}

The natural bonding orbital (NBO) analysis is a helpful tool for understanding of hydrogen bonding and delocalization of electron density from occupied Lewis-type (donor) NBOs to properly unoccupied non-Lewis type (acceptor) NBOs within the molecule [47]. The NBO analysis has been performed on NH tautomers of (1) and (2) compounds to elucidate the intramolecular charge transfer (ICT), rehybridization and delocalization of electron density within the molecules and is presented in Table IV. The second-order Fock matrix was performed to evaluate different types of donor-acceptor interactions and their stabilization energies in the NBO basis [48]. For each donor $(i)$ and acceptor $(j)$, the stabilization energy $E(2)$ associated with the delocalization $i \rightarrow j$ is determined as

$$
E 2=\Delta E_{i j}=q_{i j} \frac{F_{(i, j)}^{2}}{\varepsilon_{j}-\varepsilon_{i}},
$$

where $q_{i}$ is the donor-orbital occupancy, $\varepsilon_{j}$ and $\varepsilon_{i}$ are the energies of $\sigma$ and $\sigma *$ NBO's and $F_{(i, j)}$ is the Fock matrix element between the natural bonding orbitals. In NBO analysis, the larger the $E(2)$ value shows the more intensive interaction between electron-donors and electron-acceptors, i.e. the more electrons donating tendency from electron donors to acceptors and greater the extent of conjugation of the whole system, the possible intensive interactions are given in Table $\mathrm{V}$.

The NBO analysis for NH forms of (1) and (2) dyes have been performed on the some arylazo pyridone dyes using NBO 3.1 program [18] as implemented in the Gaussian 09 package at the B3LYP/6-31G(d,p) level. The most important interactions in the title molecules having lone pair $\mathrm{LP}(1) \mathrm{N} 3$ with that of anti-bonding $\mathrm{C}_{6} \mathrm{O}_{1}$ and the lone pair $\mathrm{LP}(1) \mathrm{N} 3$ with that of antibonding $\mathrm{C}_{2}-\mathrm{O}_{2}$, and results the stabilization of 66.92 and $67.20 \mathrm{~kJ} / \mathrm{mol}$ (for (1) and (2) molecules, respectively) and 49.69 and $49.48 \mathrm{~kJ} / \mathrm{mol}$ (for (1) and (2) molecules, respectively), which donate larger delocalization. The maximum energy transfer occurs from $\mathrm{LP}(1) \mathrm{N} 3$ to $\mathrm{C}_{6} \mathrm{O}_{1}$ and $\mathrm{C}_{2}-\mathrm{O}_{2}$. From the NBO analysis (Table V), it is noted that the maximum occupancies 1.99424, 1.99462, 1.99516 are obtained for $\mathrm{C}_{6}-\mathrm{O}_{1}, \mathrm{C}_{2}-\mathrm{O}_{2}, \mathrm{C}_{13}-\mathrm{N}_{4}$, respectively. This shows a large amount of stabilization energy.

The NBO analysis have revealed some strong intramolecular interactions, which are formed by the orbital overlap between $\sigma(\mathrm{C}-\mathrm{C})$ and $\sigma *(\mathrm{C}-\mathrm{C})$ and $\pi(\mathrm{C}-$ $\mathrm{C})$ and $\pi *(\mathrm{C}-\mathrm{C})$ bond orbital in the aromatic rings, which leads intramolecular charge transfer (ICT) to cause 
NBO results showing the formation of Lewis and non-Lewis orbitals.

TABLE IV

\begin{tabular}{|c|c|c|c|c|c|c|c|c|c|c|c|c|}
\hline & \multicolumn{5}{|c|}{ (1) } & \multicolumn{5}{|c|}{ (2) } \\
\hline & & & $\%$ & $\% s$ & $\% p$ & $\% d$ & H.O & $\%$ & $\% s$ & $\% p$ & $\% d$ & H.O \\
\hline \multirow[t]{4}{*}{$\mathrm{C}_{11}-\mathrm{C}_{10}$} & $\sigma$ & $\mathrm{C}_{11}$ & 50.19 & 35.17 & 64.79 & 0.04 & $s p^{1.84}$ & 49.38 & 34.50 & 65.46 & 0.04 & $s p^{1.90}$ \\
\hline & & $\mathrm{C}_{10}$ & 49.81 & 34.92 & 65.04 & 0.04 & $s p^{1.86}$ & 50.62 & 38.87 & 61.09 & 0.04 & $s p^{1.57}$ \\
\hline & $\pi$ & $\mathrm{C}_{11}$ & - & - & - & - & - & 47.08 & 0.00 & 99.95 & 0.04 & $s p$ \\
\hline & & $\mathrm{C}_{10}$ & - & - & - & - & - & 52.92 & 0.00 & 99.98 & 0.02 & $s p$ \\
\hline \multirow[t]{2}{*}{$\mathrm{C}_{7}-\mathrm{N}_{1}$} & $\sigma$ & $\mathrm{C}_{7}$ & 41.00 & 27.90 & 71.99 & 0.10 & $s p^{2.58}$ & 41.16 & 28.26 & 71.63 & 0.10 & $s p^{2.53}$ \\
\hline & & $\mathrm{N}_{1}$ & 59.00 & 35.25 & 64.66 & 0.08 & $s p^{1.83}$ & 58.84 & 35.31 & 64.60 & 0.08 & $s p^{1.83}$ \\
\hline \multirow[t]{2}{*}{$\mathrm{C}_{9}-\mathrm{C}_{10}$} & $\sigma$ & $\mathrm{C}_{9}$ & 50.09 & 35.04 & 64.92 & 0.04 & $s p^{2.06}$ & 49.28 & 34.37 & 65.59 & 0.04 & $s p^{1.91}$ \\
\hline & & $\mathrm{C}_{10}$ & 49.91 & 35.06 & 64.90 & 0.04 & $s p^{1.81}$ & 50.72 & 39.04 & 60.92 & 0.04 & $s p^{1.56}$ \\
\hline \multirow[t]{2}{*}{$\mathrm{C}_{10}-\mathrm{Br}$} & $\sigma$ & $\mathrm{C}_{10}$ & - & - & - & - & - & 49.56 & 22.09 & 77.81 & 0.11 & $s p^{1.91}$ \\
\hline & & $\mathrm{Br}$ & - & - & - & - & - & 50.44 & 13.85 & 85.85 & 0.29 & $s p^{6.20}$ \\
\hline \multirow[t]{4}{*}{$\mathrm{N}_{1}-\mathrm{N}_{2}$} & $\sigma$ & $\mathrm{N}_{1}$ & 45.37 & 27.55 & 72.31 & 0.13 & $s p^{2.62}$ & 45.41 & 27.57 & 72.30 & 0.13 & $s p^{2.62}$ \\
\hline & & $\mathrm{N}_{2}$ & 54.63 & 33.84 & 66.10 & 0.06 & $s p^{1.95}$ & 54.59 & 33.87 & 66.07 & 0.06 & $s p^{1.95}$ \\
\hline & $\pi$ & $\mathrm{N}_{1}$ & 42.71 & 0.12 & 99.60 & 2.24 & $s p^{99.99} d^{2.24}$ & - & - & - & - & - \\
\hline & & $\mathrm{N}_{2}$ & 57.29 & 0.11 & 99.80 & 0.08 & $s p^{99.99} d^{0.71}$ & - & - & - & - & - \\
\hline \multirow[t]{4}{*}{$\mathrm{N}_{2}-\mathrm{C}_{5}$} & $\sigma$ & $\mathrm{N}_{2}$ & 62.49 & 38.06 & 61.91 & 0.03 & $s p^{1.63}$ & 62.49 & 38.07 & 61.90 & 0.03 & $s p^{1.63}$ \\
\hline & & $\mathrm{C}_{5}$ & 37.51 & 28.59 & 71.31 & 0.10 & $s p^{2.49}$ & 37.51 & 28.63 & 71.27 & 0.10 & $s p^{2.49}$ \\
\hline & $\pi$ & $\mathrm{N}_{2}$ & - & - & - & - & - & 60.02 & 0.02 & 99.95 & 0.03 & $s p^{99.99} d^{1.57}$ \\
\hline & & $\mathrm{C}_{5}$ & - & - & - & - & - & 39.98 & 0.00 & 99.92 & 0.07 & $s p$ \\
\hline \multirow[t]{2}{*}{$\mathrm{C}_{5}-\mathrm{C}_{6}$} & $\sigma$ & $\mathrm{C}_{5}$ & 51.98 & 32.16 & 67.79 & 0.05 & $s p^{2.11}$ & 51.99 & 32.11 & 67.84 & 0.05 & $s p^{2.11}$ \\
\hline & & $\mathrm{C}_{6}$ & 48.02 & 35.96 & 63.99 & 0.05 & $s p^{1.78}$ & 48.01 & 35.90 & 64.05 & 0.05 & $s p^{1.78}$ \\
\hline \multirow[t]{2}{*}{$\mathrm{C}_{5}-\mathrm{C}_{4}$} & $\sigma$ & $\mathrm{C}_{5}$ & 49.97 & 39.18 & 60.79 & 0.03 & $s p^{1.55}$ & 49.99 & 39.19 & 60.79 & 0.03 & $s p^{1.55}$ \\
\hline & & $\mathrm{C}_{4}$ & 50.03 & 32.39 & 67.56 & 0.04 & $s p^{2.09}$ & 50.01 & 32.33 & 67.62 & 0.04 & $s p^{2.09}$ \\
\hline \multirow[t]{4}{*}{$\mathrm{C}_{6}-\mathrm{O}_{1}$} & $\sigma$ & $\mathrm{C}_{6}$ & 35.49 & 32.59 & 67.32 & 0.09 & $s p^{2.07}$ & 35.48 & 32.60 & 67.31 & 0.09 & $s p^{2.06}$ \\
\hline & & $\mathrm{O}_{1}$ & 64.51 & 39.78 & 59.89 & 0.33 & $s p^{1.51}$ & 64.52 & 39.78 & 59.89 & 0.33 & $s p^{1.51}$ \\
\hline & $\pi$ & $\mathrm{C}_{6}$ & 28.52 & 0.00 & 99.80 & 0.20 & sp & 28.56 & 0.00 & 99.80 & 0.20 & $s p$ \\
\hline & & $\mathrm{O}_{1}$ & 71.48 & 0.00 & 99.70 & 0.30 & $s p$ & 71.44 & 0.00 & 99.70 & 0.30 & $s p$ \\
\hline \multirow[t]{2}{*}{$\mathrm{C}_{6}-\mathrm{N}_{3}$} & $\sigma$ & $\mathrm{C}_{6}$ & 37.68 & 31.25 & 68.64 & 0.12 & $s p^{2.20}$ & 37.70 & 31.31 & 68.58 & 0.12 & $s p^{2.19}$ \\
\hline & & $\mathrm{N}_{3}$ & 62.32 & 36.77 & 63.19 & 0.03 & $s p^{1.72}$ & 62.30 & 36.77 & 63.20 & 0.03 & $s p^{1.72}$ \\
\hline \multirow[t]{4}{*}{$\mathrm{C}_{4}-\mathrm{C}_{3}$} & $\sigma$ & $\mathrm{C}_{4}$ & 50.10 & 34.73 & 65.23 & 0.04 & $s p^{1.88}$ & 50.09 & 34.74 & 65.22 & 0.04 & $s p^{1.88}$ \\
\hline & & $\mathrm{C}_{3}$ & 49.90 & 37.48 & 62.49 & 0.03 & $s p^{1.67}$ & 49.91 & 37.50 & 62.47 & 0.03 & $s p^{1.67}$ \\
\hline & $\pi$ & $\mathrm{C}_{4}$ & 42.79 & 0.00 & 99.93 & 0.06 & $s p$ & 42.97 & 0.00 & 99.93 & 0.06 & $s p$ \\
\hline & & $\mathrm{C}_{3}$ & 57.21 & 0.00 & 99.98 & 0.02 & sp & 57.03 & 0.00 & 99.98 & 0.02 & $s p$ \\
\hline \multirow[t]{2}{*}{$\mathrm{C}_{4}-\mathrm{C}_{14}$} & $\sigma$ & $\mathrm{C}_{4}$ & 51.48 & 32.85 & 67.11 & 0.03 & $s p^{2.04}$ & 51.51 & 32.90 & 67.06 & 0.03 & $s p^{2.04}$ \\
\hline & & $\mathrm{C}_{14}$ & 48.52 & 30.21 & 69.75 & 0.04 & $s p^{2.31}$ & 48.49 & 30.19 & 69.77 & 0.04 & $s p^{2.31}$ \\
\hline \multirow[t]{2}{*}{$\mathrm{C}_{3}-\mathrm{C}_{2}$} & $\sigma$ & $\mathrm{C}_{3}$ & 52.70 & 31.62 & 68.34 & 0.04 & $s p^{2.16}$ & 52.71 & 31.59 & 68.37 & 0.04 & $s p^{2.16}$ \\
\hline & & $\mathrm{C}_{2}$ & 47.30 & 37.20 & 62.75 & 0.05 & $s p^{1.69}$ & 47.29 & 37.17 & 62.77 & 0.05 & $s p^{1.69}$ \\
\hline $\mathrm{C}_{3}-\mathrm{C}_{13}$ & $\sigma$ & $\mathrm{C}_{3}$ & 51.49 & 30.87 & 69.09 & 0.05 & $s p^{2.24}$ & 51.51 & 30.87 & 69.08 & 0.05 & $s p^{2.24}$ \\
\hline & & $\mathrm{C}_{13}$ & 48.51 & 52.47 & 47.50 & 0.04 & $s p^{0.91}$ & 48.49 & 52.45 & 47.52 & 0.04 & $s p^{0.91}$ \\
\hline $\mathrm{C}_{2}-\mathrm{N}_{3}$ & $\sigma$ & $\mathrm{C}_{2}$ & 36.58 & 29.36 & 70.51 & 0.13 & $s p^{2.40}$ & 36.58 & 29.38 & 70.49 & 0.13 & $s p^{2.40}$ \\
\hline & & $\mathrm{N}_{3}$ & 63.42 & 35.96 & 64.01 & 0.03 & $s p^{1.78}$ & 63.42 & 35.93 & 64.04 & 0.03 & $s p^{1.78}$ \\
\hline $\mathrm{C}_{2}-\mathrm{O}_{2}$ & $\sigma$ & $\mathrm{C}_{2}$ & 35.31 & 33.24 & 66.67 & 0.09 & $s p^{2.01}$ & 35.31 & 33.25 & 66.66 & 0.09 & $s p^{2.01}$ \\
\hline & & $\mathrm{O}_{2}$ & 64.69 & 41.04 & 58.60 & 0.36 & $s p^{1.43}$ & 64.69 & 41.05 & 58.59 & 0.36 & $s p^{1.43}$ \\
\hline & $\pi$ & $\mathrm{C}_{2}$ & 32.03 & 0.00 & 99.83 & 0.17 & $\mathrm{sp}$ & 32.12 & 0.00 & 99.83 & 0.17 & $\mathrm{sp}$ \\
\hline & & $\mathrm{O}_{2}$ & 67.97 & 0.00 & 99.67 & 0.33 & $s p^{1.74}$ & 67.88 & 0.00 & 99.67 & 0.33 & $s p$ \\
\hline $\mathrm{C}_{13}-\mathrm{N}_{4}$ & $\sigma$ & $\mathrm{C}_{13}$ & 42.53 & 47.64 & 52.34 & 0.02 & $s p^{1.10}$ & 42.54 & 47.65 & 52.32 & 0.02 & $s p^{1.10}$ \\
\hline & & $\mathrm{N}_{4}$ & 57.47 & 45.88 & 53.78 & 0.34 & $s p^{1.17}$ & 57.46 & 45.85 & 53.81 & 0.34 & $s p^{1.17}$ \\
\hline & $\pi$ & $\mathrm{C}_{13}$ & 46.52 & 0.03 & 99.92 & 0.05 & $s p^{99.99} \mathrm{~d}^{1.76}$ & 46.54 & 0.03 & 99.92 & 0.05 & $s p^{99.99} \mathrm{~d}^{1.73}$ \\
\hline & & $\mathrm{N}_{4}$ & 53.48 & 0.01 & 99.61 & 0.38 & $s p^{99.99} d^{36.95}$ & 53.46 & 0.01 & 99.61 & 0.38 & $s p^{99.99} \mathrm{~d}^{36.20}$ \\
\hline & $\pi_{2}$ & $\mathrm{C}_{13}$ & 45.76 & 0.00 & 99.95 & 0.05 & $s p$ & 45.84 & 0.00 & 99.95 & 0.05 & $s p$ \\
\hline & & $\mathrm{N}_{4}$ & 54.24 & 0.00 & 99.63 & 0.37 & $s p$ & 54.16 & 0.00 & 99.63 & 0.37 & $s p$ \\
\hline $\mathrm{C}_{14}-\mathrm{C}_{19}$ & $\sigma$ & $\mathrm{C}_{14}$ & 51.46 & 34.79 & 65.17 & 0.03 & $s p^{1.87}$ & 51.47 & 34.80 & 65.17 & 0.03 & $s p^{1.87}$ \\
\hline & & $\mathrm{C}_{19}$ & 48.54 & 34.69 & 65.27 & 0.04 & $s p^{2.06}$ & 48.53 & 34.68 & 65.28 & 0.04 & $s p^{1.88}$ \\
\hline
\end{tabular}


NBO results showing the formation of Lewis and non-Lewis orbitals. TABLE IV cont.

\begin{tabular}{|c|c|c|c|c|c|c|c|c|c|c|c|}
\hline & \multicolumn{5}{|c|}{$(1)$} & \multicolumn{5}{|c|}{$(2)$} \\
\hline & & $\%$ & $\% s$ & $\% p$ & $\% d$ & H.O & $\%$ & $\% s$ & $\% p$ & $\% d$ & H.O \\
\hline LP1 & N1 & - & 37.22 & 62.70 & 0.08 & $s p^{1.68}$ & - & 37.19 & 62.73 & 0.08 & $s p^{1.69}$ \\
\hline LP1 & O1 & - & 59.68 & 40.28 & 0.04 & $s p^{0.67}$ & - & 59.66 & 40.30 & 0.04 & $s p^{0.68}$ \\
\hline LP2 & O1 & - & 0.51 & 99.27 & 0.22 & $s p^{99.99}$ & - & 0.53 & 99.25 & 0.22 & $s p^{99.99} d^{0.42}$ \\
\hline LP1 & O2 & - & 58.92 & 41.03 & 0.05 & $s p^{0.70}$ & - & 58.91 & 41.04 & 0.05 & $s p^{0.70}$ \\
\hline LP2 & O2 & - & 0.00 & 99.75 & 0.25 & $s p$ & - & 0.00 & 99.75 & 0.25 & $s p$ \\
\hline LP1 & N3 & - & 0.01 & 99.98 & 0.01 & $s p$ & - & 0.01 & 99.98 & 0.01 & $s p$ \\
\hline LP1 & N4 & - & 54.18 & 45.76 & 0.06 & $s p^{0.84}$ & - & 54.21 & 45.73 & 0.06 & $s p^{0.84}$ \\
\hline LP1 & $\mathrm{Br}$ & - & - & - & - & - & - & 86.46 & 13.54 & 0.00 & $s p^{0.16}$ \\
\hline LP3 & $\mathrm{Br}$ & - & - & - & - & - & - & 0.00 & 99.96 & 0.04 & $s p$ \\
\hline
\end{tabular}

stabilization of the system. The strong intramolecular hyperconjugative interaction of the $\sigma$ and $\pi$ electrons of $\mathrm{C}-\mathrm{C}$ to the anti- $\mathrm{C}-\mathrm{C}$ bond of the aromatic rings results to stabilization of some part of the rings as evident from Table V. Such as, $\sigma(\mathrm{C} 8-\mathrm{C} 9)$ distribute to $\sigma *(\mathrm{C} 7-$ $\mathrm{C} 8), \sigma *(\mathrm{C} 9-\mathrm{C} 10)$ and $\sigma *(\mathrm{C} 10-\mathrm{Br})$ leading to stabilization of $\approx 2.3, \approx 2.8 \mathrm{kcal} / \mathrm{mol}$ for both molecules, respectively, and $4.67 \mathrm{kcal} / \mathrm{mol}$ for (2) molecule. This enhanced further conjugate with antibonding orbital of $\pi *\left(\mathrm{C}_{11^{-}}\right.$ $\left.\mathrm{C}_{10}\right), \pi *\left(\mathrm{C}_{12}-\mathrm{C}_{7}\right)$, which results to strong delocalization of 20.21 and $18.96 \mathrm{kcal} / \mathrm{mol}$ for (2) molecule, respectively. The same kind of interaction is studied in the $\left(\mathrm{C}_{11}\right.$ $\left.\mathrm{C}_{10}\right)$ and $\left(\mathrm{C}_{12}-\mathrm{C}_{7}\right)$ bonds for (2) molecule as given in Table V. In hydrazone forms for (1) and (2) molecules, electron donating from a lone pair orbital on the oxygen atom, $\mathrm{LP}(1) \mathrm{O} 1$, to the anti-bonding acceptor $\sigma *(\mathrm{~N}-\mathrm{H})$ orbitals in the basal position, e.g., LP(1) transfers electron density from the oxygen $\operatorname{LP}(1) \mathrm{O} 1 \rightarrow \sigma^{*}(\mathrm{~N} 2-\mathrm{H})$. As shown in Table IV, the LP(1) O orbitals have 5968 and $59.66 \% p$-character and are occupied by 1.97439 and 1.97435 electrons. From Table V, the stabilisation energy $E(2)$ associated with the hyperconjugative interaction $n(\mathrm{O} 1) \rightarrow \sigma^{*}(\mathrm{~N} 2-\mathrm{H})$ obtained is 1.73 and $1.76 \mathrm{kcal} / \mathrm{mol}$, respectively.

\subsection{Vibrational (FT-IR) analysis}

The experimental vibrational spectra of (2) compound have been obtained by Alimmari et al. [11]. However, any theoretical data of (1) and (2) compounds for vibrational analyses have not been given in literature. We have simulated the theoretical vibrational spectra of the (1) and (2) compounds by using B3LYP method with 6-31G(d,p) basis set. In this study the calculated $\mathrm{NH}$ stretching vibrations $\left(3108 \mathrm{~cm}^{-1}\right)$ of (1) and (2) hydrazone tautomeric forms was closer ( $2 \%$ lower) than the $\mathrm{OH}$ stretching vibrations (3333 and $3347 \mathrm{~cm}^{-1}$ of (1) and (2) compounds, respectively) to the experimental frequency $\left(3170 \mathrm{~cm}^{-1}\right)$. Therefore, the vibrational frequencies, IR intensities and the forms of vibrations for NH tautomers of (1) and (2) compounds calculated using B3LYP/6-31G(d,p) method are listed in Table VI in comparison with the experimental [11] results. Then, a detailed vibrational study on the basis of PED was performed by means of VEDA 4

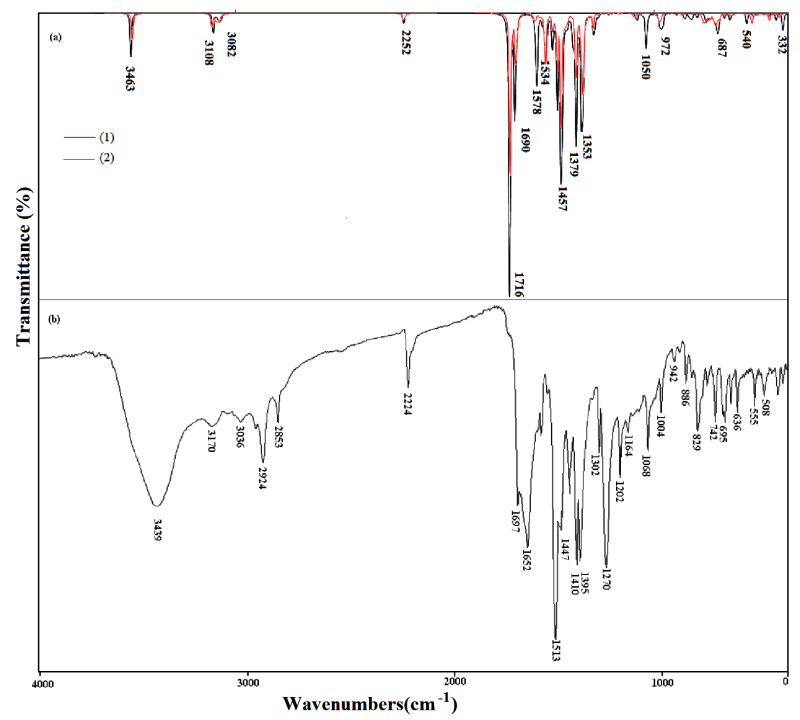

Fig. 6. (a) The simulated FT-IR spectrum computed at B3LYP level with $6-31 \mathrm{G}(\mathrm{d}, \mathrm{p})$ basis set for hydrazone tautomers of (1) and (2) molecules. (b) The experimental FT-IR spectrum of (2) compound from Ref. [11].

program [16] based on the results of B3LYP level. This reveals good correspondence between theory and experiment in main spectral features. For a visual comparison, the recorded [11] and calculated FT-IR spectra for NH forms of (1) and (2) compounds are presented in Fig. 6. As seen in Fig. 6, the experimental fundamentals are in better agreement with the scaled fundamentals.

\subsection{1. $N-H$ vibration}

In earlier study, the IR spectra of the imino group $(\mathrm{N}-\mathrm{H})$ stretching in 2-pyridone ring (2PY) was observed that some free $\nu_{N H}$ frequencies were found at ca. $3100 \mathrm{~cm}^{-1}$ and at $2850 \mathrm{~cm}^{-1}$ in dilute $\mathrm{CCl}_{4}$ solutions and in the gas phase at $3448 \mathrm{~cm}^{-1}$ and were calculated $\left(\mathrm{HF} / 6-31 \mathrm{G}\right.$ level) at $3462.78 \mathrm{~cm}^{-1}$ frequencies [49]. In this present study, the imino group $(\mathrm{N}-\mathrm{H})$ stretching of heterocyclic pyridone ring (see Fig. 7) which is contributing to $100 \%$ of PED was calculated as 3464 and $3463 \mathrm{~cm}^{-1}$ for hydrazone tautomers of (1) and (2) compounds by using the B3LYP methods with $6-31 \mathrm{G}(\mathrm{d}, \mathrm{p})$ 
TABLE V

The second-order perturbation theory analysis of Fock matrix in natural bond orbital (NBO basis) for the hydrazone tautomer of (1) and (2) molecules.

\begin{tabular}{|c|c|c|c|c|c|c|c|c|c|c|c|c|c|}
\hline \multirow[b]{2}{*}{ Donor (i) } & \multirow[b]{2}{*}{ Type } & \multicolumn{2}{|c|}{$\overline{\mathrm{ED}(\mathrm{i})(\mathrm{e})}$} & \multirow[t]{2}{*}{ Acceptor (j) } & \multirow[t]{2}{*}{ Type } & \multicolumn{2}{|c|}{$E D(j)(e)$} & \multicolumn{2}{|c|}{$\mathrm{E}(2)^{a}[\mathrm{kcal} / \mathrm{mol}]$} & \multicolumn{2}{|c|}{$\varepsilon(\mathrm{j})-\varepsilon(\mathrm{i})^{b}$ [a.u.] } & \multicolumn{2}{|c|}{$\mathrm{F}(\mathrm{i}, \mathrm{j})^{c}$ [a.u.] } \\
\hline & & (1) & $(2)$ & & & (1) & $(2)$ & $(1)$ & $(2)$ & $(1)$ & $(2)$ & $(1)$ & $(2)$ \\
\hline $\mathrm{C}_{11}-\mathrm{C}_{12}$ & $\sigma$ & 1.97810 & 1.97058 & $7-\mathrm{N}_{1}$ & $\sigma *$ & 0.02284 & 0.02204 & 4.50 & 4.33 & 1.14 & 1.15 & 0.064 & 0.063 \\
\hline $\mathrm{C}_{11}-\mathrm{C}_{10}$ & $\sigma$ & 98120 & 1.98197 & ${ }_{1}-\mathrm{C}_{12}$ & $\sigma *$ & 0.01447 & 0.01568 & 2.54 & 2.55 & 1.28 & 1.31 & 0.051 & 0.052 \\
\hline $\mathrm{C}_{12}-\mathrm{C}_{7}$ & $\sigma$ & 1.97885 & 1.97912 & $\mathrm{C}_{7}-\mathrm{C}_{8}$ & $\sigma *$ & 0.02234 & 0.02209 & 3.72 & 3.61 & 1.26 & 1.26 & 0.061 & 0.060 \\
\hline \multirow[t]{2}{*}{$\mathrm{C}_{7}-\mathrm{C}_{8}$} & $\sigma$ & 1.97296 & 1.97319 & $\mathrm{C}_{12}-\mathrm{C}_{7}$ & $\sigma *$ & 0.03231 & 0.03254 & 3.50 & 3.36 & 1.24 & 1.24 & 0.059 & 0.058 \\
\hline & & & & $\mathrm{N}_{1}-\mathrm{N}_{2}$ & & 0.01818 & 0.01762 & 2.87 & 2.90 & 1.17 & 1.17 & 0.052 & 0.052 \\
\hline $\mathrm{C}_{7}-\mathrm{N}_{1}$ & $\sigma$ & 1.98107 & 1.98105 & $\mathrm{~N}_{2}-\mathrm{C}_{5}$ & $\sigma *$ & 0.02575 & 0.02544 & 5.40 & 5.30 & 1.26 & 1.27 & 0.074 & 0.073 \\
\hline \multirow[t]{5}{*}{$\mathrm{C}_{8}-\mathrm{C}_{9}$} & $\sigma$ & 1.97984 & 1.97194 & $\mathrm{C}_{7}-\mathrm{C}_{8}$ & $\sigma *$ & 0.02234 & 0.02209 & 2.40 & 2.33 & 1.25 & 1.25 & 0.049 & 0.048 \\
\hline & & & & $\mathrm{C}_{9}-\mathrm{C}_{10}$ & & 0.01552 & 0.02527 & 2.47 & 2.84 & 1.27 & 1.15 & 0.050 & 0.051 \\
\hline & & & & $\mathrm{C}_{10}-\mathrm{Br}$ & & & 0.03026 & - & 4.67 & - & 0.80 & - & 0.055 \\
\hline & $\pi$ & 1.66282 & 1.66914 & $\mathrm{C}_{11}-\mathrm{C}_{10}$ & $\pi *$ & & 0.39409 & - & 20.21 & - & 0.27 & - & 0.067 \\
\hline & & & & & & & 0.43158 & - & 18.96 & - & 0.27 & - & 0.066 \\
\hline $\mathrm{C}_{9}-\mathrm{C}_{10}$ & $\sigma$ & 1.98138 & 1.98213 & $\mathrm{C}_{8}-\mathrm{C}_{9}$ & $\sigma *$ & 0.01374 & 0.01491 & 2.49 & 2.50 & 1.28 & 1.31 & 0.050 & 0.051 \\
\hline $\mathrm{C}_{10}-\mathrm{Br}$ & $\sigma$ & & 1.98634 & $\mathrm{C}_{11}-\mathrm{C}_{12}$ & $\sigma *$ & 0.01447 & 0.01568 & - & 2.88 & - & 1.22 & - & 0.053 \\
\hline $\mathrm{N}_{1}-\mathrm{N}_{2}$ & $\sigma$ & 1.98883 & 1.98857 & $\mathrm{~N}_{2}-\mathrm{C}_{5}$ & $\sigma *$ & 0.02575 & 0.02544 & 2.44 & 2.46 & 1.44 & 1.44 & 0.053 & 0.053 \\
\hline $\mathrm{N}_{2}-\mathrm{C}_{5}$ & $\sigma$ & 8341 & 346 & $\mathrm{C}_{7}-\mathrm{N}_{1}$ & $\sigma *$ & 0.02284 & 0.02204 & 2.66 & .66 & 1.31 & 1.31 & .053 & 0.053 \\
\hline $\mathrm{C}_{5}-\mathrm{C}_{6}$ & $\sigma$ & 1.97026 & 1.97019 & $-\mathrm{N}_{2}$ & $\sigma *$ & 0.01818 & 0.01762 & 5.91 & 5.95 & 1.16 & 1.16 & 0.074 & 0.074 \\
\hline \multirow[t]{2}{*}{$\mathrm{C}_{5}-\mathrm{C}_{4}$} & $\sigma$ & 1.96945 & 1.96949 & & $\sigma *$ & 2575 & 2544 & 2.04 & 05 & 1.17 & .17 & .044 & 0.044 \\
\hline & & & & $\mathrm{C}_{4}-\mathrm{C}_{3}$ & & 0.02936 & 0.02938 & 3.25 & 3.23 & 1.30 & 1.30 & 0.058 & 0.058 \\
\hline \multirow[t]{2}{*}{$\mathrm{C}_{6}-\mathrm{N}_{3}$} & $\sigma$ & 1.98789 & 1.98790 & & $\sigma *$ & 0.02575 & 544 & 1.80 & .78 & 1.30 & 1.30 & 0.043 & 0.043 \\
\hline & & & & $\mathrm{C}_{2}-\mathrm{O}_{2}$ & & 0.00849 & 0.00846 & 1.96 & 1.96 & 1.45 & 1.45 & 0.048 & 0.048 \\
\hline \multirow{2}{*}{$\mathrm{C}_{4}-\mathrm{C}_{3}$} & $\sigma$ & 1.96405 & 1.96415 & & $\sigma *$ & 0.02575 & 544 & 4.51 & 4.49 & 1.19 & 1.19 & .065 & 0.065 \\
\hline & & & & $\mathrm{C}_{13}-\mathrm{N}_{4}$ & & 0.00964 & 0.00963 & 4.24 & 4.24 & 1.64 & 1.64 & 0.075 & 0.075 \\
\hline \multirow[t]{2}{*}{$\mathrm{C}_{4}-\mathrm{C}_{3}$} & $\pi$ & 1.76485 & 1.76469 & & & 0.29077 & 0.2 & 23.70 & 23.50 & 0.29 & 0.29 & 0.075 & 0.075 \\
\hline & & & & $\mathrm{C}_{13}-\mathrm{N}_{4}$ & $\pi_{2} *$ & 0.08638 & 0.08529 & 18.69 & 18.54 & 0.40 & 0.40 & 0.080 & 0.080 \\
\hline \multirow[t]{2}{*}{$\mathrm{C}_{4}-\mathrm{C}_{14}$} & $\sigma$ & 1.96772 & 1.96771 & & $\sigma *$ & 0.02936 & 0.0 & 3.41 & 3.44 & 1.23 & 1.23 & 0.058 & 0.058 \\
\hline & & & & $\mathrm{C}_{3}-\mathrm{C}_{2}$ & & 0.07231 & 0.07251 & 3.49 & 3.50 & 1.09 & 1.09 & 0.056 & 0.056 \\
\hline \multirow[t]{3}{*}{$\mathrm{C}_{3}-\mathrm{C}_{2}$} & $\sigma$ & 1.96832 & 1.96838 & $\mathrm{C}_{4}-\mathrm{C}_{14}$ & $\sigma *$ & 0.03052 & 0.03056 & 3.30 & 3.31 & 1.13 & 1.13 & 0.054 & 0.055 \\
\hline & & & & $\mathrm{C}_{13}-\mathrm{N}_{4}$ & & 0.00964 & 0.00963 & 3.90 & 3.89 & 1.59 & 1.59 & 0.071 & 0.070 \\
\hline & & & & $\mathrm{C}_{13}-\mathrm{N}_{4}$ & $\pi *$ & 0.01516 & 0.01513 & 2.55 & 2.55 & 0.81 & 0.81 & 0.041 & 0.041 \\
\hline $\mathrm{C}_{3}-\mathrm{C}_{13}$ & $\sigma$ & 1.97743 & 1.97742 & $\mathrm{C}_{2}-\mathrm{N}_{3}$ & $\sigma *$ & 0.08752 & 0.08759 & 2.65 & 2.65 & 1.13 & 1.13 & 0.050 & 0.050 \\
\hline & & & & $\mathrm{C}_{13}-\mathrm{N}_{4}$ & & 0.00964 & 0.00963 & 5.96 & 5.96 & 1.63 & 1.63 & 0.088 & 0.088 \\
\hline $\mathrm{C}_{2}-\mathrm{N}_{3}$ & $\sigma$ & 1.98760 & 1.98759 & $\mathrm{C}_{6}-\mathrm{O}_{1}$ & $\sigma *$ & 0.01013 & 0.01015 & 2.97 & 2.99 & 1.37 & 1.37 & 0.057 & 0.057 \\
\hline $\mathrm{C}_{6}-\mathrm{O}_{1}$ & & 1.99424 & & $-\mathrm{N}_{3}$ & $\sigma *$ & 0.07121 & - & 1.74 & - & 1.47 & - & 0.046 & - \\
\hline $\mathrm{C}_{2}-\mathrm{O}_{2}$ & $\sigma$ & 1.99462 & 463 & & $\sigma *$ & 0.07121 & 0.07099 & 1.67 & 1.67 & 1.51 & 1.51 & 0.046 & 0.046 \\
\hline $\mathrm{C}_{13}-\mathrm{N}_{4}$ & $\sigma$ & 1.99516 & 1.99515 & $\mathrm{C}_{13}$ & $\sigma *$ & 0.02849 & 0.02851 & 6.46 & 6.46 & 1.55 & 1.55 & 0.090 & 0.090 \\
\hline $\mathrm{C}_{13}-\mathrm{N}_{4}$ & $\pi_{2}$ & 1.95219 & 1.95119 & & $\pi *$ & 0.28820 & 0.28498 & 8.76 & 8.84 & 0.33 & 0.33 & 0.051 & 0.052 \\
\hline $\mathrm{LP}(1) \mathrm{N} 1$ & & 1.92940 & 1.92925 & $\mathrm{C}_{12}-\mathrm{C}_{7}$ & $\sigma *$ & 0.03231 & 0.03254 & 8.04 & 8.38 & 0.95 & 0.94 & 0.079 & 0.080 \\
\hline $\mathrm{LP}(2) \mathrm{N} 1$ & & & - & $\mathrm{C}_{12}-\mathrm{C}_{7}$ & $\pi *$ & & 0.43158 & - & 42.60 & - & 0.22 & - & 0.097 \\
\hline $\mathrm{LP}(2) \mathrm{N} 1$ & & & - & $\mathrm{N}_{2}-\mathrm{C}_{5}$ & $\pi *$ & & 0.69873 & - & 100.06 & - & 0.14 & - & 0.111 \\
\hline $\mathrm{LP}(1) \mathrm{O} 1$ & & 1.97439 & 1.97435 & & $\sigma *$ & 0.06479 & 0.06506 & 3.61 & 3.62 & 1.12 & 1.12 & 0.057 & 0.057 \\
\hline $\mathrm{LP}(2) \mathrm{O} 1$ & & 1.84682 & 1.84634 & $\mathrm{C}_{5}-\mathrm{C}_{6}$ & & 0.06479 & 0.06506 & 17.13 & 17.15 & 0.70 & 0.70 & 0.100 & 0.100 \\
\hline & & & & $\mathrm{C}_{6}-\mathrm{N}_{3}$ & & 0.07121 & 0.07099 & 24.86 & 24.83 & 0.72 & 0.72 & 0.122 & 0.122 \\
\hline $\mathrm{LP}(1) \mathrm{N} 3$ & & 1.62906 & 1.62850 & $\mathrm{C}_{6}-\mathrm{O}_{1}$ & $\pi *$ & 0.37347 & 0.37208 & 66.92 & 67.20 & 0.26 & 0.26 & 0.118 & 0.119 \\
\hline & & & & $\mathrm{C}_{2}-\mathrm{O}_{2}$ & & 0.29077 & 0.28835 & 49.69 & 49.48 & 0.29 & 0.29 & 0.108 & 0.108 \\
\hline $\mathrm{LP}(1) \mathrm{N} 4$ & & 1.96925 & 1.96925 & $\mathrm{C}_{3}-\mathrm{C}_{13}$ & $\sigma *$ & 0.02849 & 0.02851 & 12.87 & 12.89 & 1.02 & 1.02 & 0.103 & 0.103 \\
\hline $\mathrm{LP}(2) \mathrm{O} 2$ & & 1.85715 & 1.85693 & $\mathrm{C}_{3}-\mathrm{C}_{2}$ & & 0.07231 & 0.07251 & 21.05 & 21.12 & 0.68 & 0.68 & 0.109 & 0.109 \\
\hline & & & & $\mathrm{C}_{2}-\mathrm{N}_{3}$ & & 0.08752 & 0.08759 & 28.61 & 28.66 & 0.66 & 0.66 & 0.124 & 0.124 \\
\hline $\mathrm{LP}(2) \mathrm{Br}$ & & & 1.97497 & $\mathrm{C}_{11}-\mathrm{C}_{10}$ & & 0.01545 & 0.02526 & - & 3.07 & - & 0.84 & - & 0.045 \\
\hline
\end{tabular}

${ }^{a} \mathrm{E}(2)$ means energy of hyperconjugative interactions, ${ }^{b}$ Energy difference between donor and acceptor $i$ and $j$ NBO orbitals, ${ }^{c} F_{i j}$ is the Fock matrix element between $i$ and $j$ NBO orbitals. 


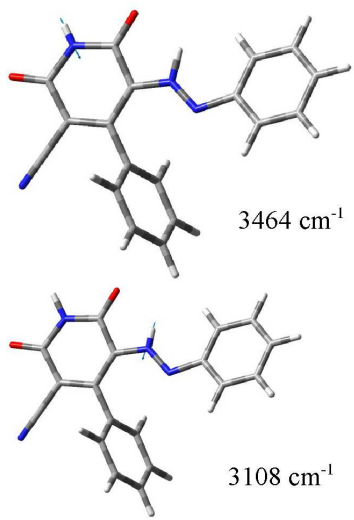

b)

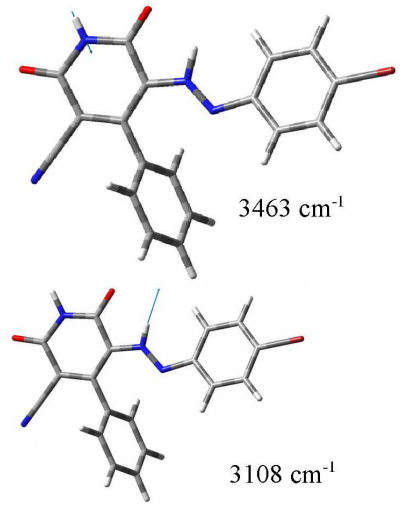

Fig. 7. Vector representation for the main infrared active normal modes calculated at B3LYP/6-31G(d,p) level for the hydrazone species of (a) (1) and (b) (2) compounds.

basis set, respectively. This stretching has been observed at $3439 \mathrm{~cm}^{-1}$ [11]. In the present investigation, the $\mathrm{N}-\mathrm{H}$ stretching vibrations of hydrazone tautomeric forms have been found very weak band at $3170 \mathrm{~cm}^{-1}$. The calculated $\mathrm{N}-\mathrm{H}$ stretching vibrations for hydrazone tautomers of (1) and (2) compounds (see Fig. 6) are both at $3108 \mathrm{~cm}^{-1}$ using B3LYP methods with 6-31G $(\mathrm{d}, \mathrm{p})$ basis set. These N$\mathrm{H}$ vibrations of hydrazone tautomers are most pure mode as evidenced from $98 \%$ of PED in (1) and (2) compounds.

\subsection{2. $C-H$ vibrations}

The hetero aromatic structure shows the presence of $\mathrm{C}-\mathrm{H}$ stretching vibrations in the region $3100-3000 \mathrm{~cm}^{-1}$ which is the characteristic region for the ready identification of $\mathrm{C}-\mathrm{H}$ stretching vibrations [50]. The $\mathrm{B} 3 \mathrm{LYP} / 6-31 \mathrm{G}(\mathrm{d}, \mathrm{p})$ calculations give bands in the range $3096-3054 \mathrm{~cm}^{-1}$ and $3102-3058 \mathrm{~cm}^{-1}$ for (1) and (2) compounds, respectively, as $\mathrm{m}(\mathrm{CH})$ modes. As indicated by PED, these modes involve exact contribution of $>92 \%$ suggesting that they are pure stretching modes. In this region, the bands are not affected remarkably by the nature of the substituent.

The $\mathrm{C}-\mathrm{H}$ out of plane deformation is observed between 1000 and $700 \mathrm{~cm}^{-1}$ [51]. The calculated out of plane bending vibrations at B3LYP method give the mode at $745,753,808,822,895,933,940,962 \mathrm{~cm}^{-1}$ (748, 793, $821,823,895,932,934,951,962 \mathrm{~cm}^{-1}$ for (2) compound) for (1) compound.

\subsection{3. $C=N$ and $C \equiv N$ vibrations}

The bands in the region of $1300-1200 \mathrm{~cm}^{1}$ are due to $\mathrm{C}=\mathrm{N}$ stretching vibrations, which shift the wave number and intensity in a coordination compound fashion depending on the neighbouring group, conjugation effects, H-bonding and molecular tautomerism [52]. The bands appearing in the IR spectrum at 1447, 1395, 1270, and $1202 \mathrm{~cm}^{-1}$ correspond to the stretching vibrations of the $\mathrm{C}=\mathrm{N}$ group. The calculated bands are 1455 (15\%), 1382 $(12 \%), 1265(12 \%)$ and $1214(29 \%) \mathrm{cm}^{-1}(1453,1381$, 1266 and $1215 \mathrm{~cm}^{-1}$ for (2) compound) at the B3LYP $/ 6$ $31 \mathrm{G}(\mathrm{d}, \mathrm{p})$ level for the $\mathrm{C}=\mathrm{N}$ vibrational modes. The ob- tained results are consistent with the previous report concerning 5-(4-, 3- and 2-methoxyphenylazo)-3-cyano1-ethyl-6-hydroxy-4-methyl-2-pyridone [31].

Unsaturated or aromatic nitriles, in which the double bond or ring is adjacent to the $\mathrm{C} \equiv \mathrm{N}$ group, absorbs more strongly in the infrared than saturated compounds, and the related band occurs at somewhat lower frequency near $2230 \mathrm{~cm}^{-1}$ [53]. In our present work, theoretically computed value $\left(\nu_{15}\right)$ is assigned to the stretching of $\mathrm{C} \equiv \mathrm{N}$ group which is contributing to $89 \%$ of $\mathrm{PED}$, and it is in a good agreement with our experimental spectrum; the observed band in FT-IR spectrum is at $2224 \mathrm{~cm}^{-1}$. The vibrational modes $\left(\nu_{15}\right)$, which are calculated at $2249 \mathrm{~cm}^{-1}$ for (1) and (2) compounds are assigned to the in-plane stretching vibration of $\mathrm{C} \equiv \mathrm{N}$ group.

\subsection{4. $C=O$ vibrations}

The structural unit of carbonyl $(\mathrm{C}=\mathrm{O})$ has an excellent group frequency which is described as a stretching vibration, and this group has been most extensively studied by infrared spectroscopy. Compounds containing the carbonyl group present a very intense and narrow peak in the infrared region, placed within $1800-1600 \mathrm{~cm}^{-1}$, referring to the stretching vibration of the $\mathrm{C}=\mathrm{O}$ bond, $\nu(\mathrm{C}=\mathrm{O})$. The double bond between the carbon-oxygen atoms is formed by $\pi-\pi$ bonding between carbon and oxygen. Because these atoms have different electronegativities, the bonding electrons are not equally distributed between the two atoms [54]. The calculated absorptions at $\approx 1715(84 \%)$ and $\approx 1686(67 \%) \mathrm{cm}^{-1}$ for hydrazone forms of both compounds by B3LYP/6-31G(d,p) method are modes 16 and 17 , respectively, which belongs to the stretching of bond $\mathrm{C}=\mathrm{O}$ of pyridine ring.

\subsection{5. $C-B r$ vibrations}

Bromine compounds absorb strongly in the region 650 $450 \mathrm{~cm}^{-1}$ due to the $\mathrm{CBr}$ stretching vibrations [55]. In the spectra of $(2)$ molecule the $\nu(\mathrm{C}-\mathrm{Br})$ stretching vibration contributes to the bands computed at 333, 540, and $1048 \mathrm{~cm}^{-1}$ (which is contributing to 24,12 and $12 \%$, respectively) by B3LYP $/ 6-31 \mathrm{G}(\mathrm{d}, \mathrm{p})$ method (modes 96 , 84, and 50, respectively, in Table VI). These results show excellent agreement with the assignment reported earlier [56]. According to the calculated PED, the out-ofplane $\gamma(\mathrm{C}-\mathrm{Br})$ bending vibration in (2) should be assigned to the band at 330 (mode 97 ).

\section{Conclusions}

The molecular structures and quantum chemical parameters for the hydrazone and azo forms of (1) and (2) dyes were studied using B3LYP method at 6-31G(d,p) basis set. Calculated results reveal that the hydrazone form of (1) and (2) compounds are more stable than azo form in gas phase. NLO behaviors for the azo and hydrazone forms of (1) and (2) molecules were investigated by determining the dipole moment $\mu(D)$, the polarizability $\langle\alpha\rangle$ (in a.u. and esu), the anisotropic of the polarizabilities $\langle\Delta \alpha\rangle$ (in a.u.) and the first-order 
TABLE VI

Comparison of the experimental FT-IR wave numbers $\left[\mathrm{cm}^{-1}\right]$ for (2) compound and theoretical harmonic wave numbers $\left[\mathrm{cm}^{-1}\right]$ for hydrazone tautomer of (1) and (2) by B3LYP/6-31G(d,p) method.

\begin{tabular}{|c|c|c|c|c|c|c|c|c|c|c|}
\hline \multirow[b]{2}{*}{$\nu$} & \multirow[b]{2}{*}{ Assignments $\left(\% \mathrm{PED}^{d}\right)$} & \multirow[b]{2}{*}{$\operatorname{Expt}^{a}$} & \multicolumn{3}{|c|}{ (1) } & \multicolumn{2}{|c|}{ Theoretical } & \multicolumn{3}{|c|}{$(2)$} \\
\hline & & & $\mathrm{A}^{b}$ & $\mathrm{~B}^{c}$ & IR int. & $\mathrm{R}$ act. & $\mathrm{A}^{b}$ & $\mathrm{~B}^{c}$ & IR Int. & $\mathrm{R}$ act. \\
\hline 1 & $\nu(\mathrm{NH})_{\mathrm{pyr}}(100)$ & 3439 & 3605 & 3464 & 97 & 187 & 3604 & 3463 & 102 & 198 \\
\hline 2 & $\nu(\mathrm{NH})$ & 3170 & 3236 & 3108 & 46 & 420 & 3236 & 3108 & 46 & 753 \\
\hline 3 & $\nu(\mathrm{CH})_{\mathrm{ph} 1}(98)$ & & 3222 & 3096 & 11 & 164 & 3229 & 3102 & 3 & 133 \\
\hline 4 & $\nu(\mathrm{CH})_{\mathrm{ph} 1}(95)$ & & - & - & - & - & 3224 & 3098 & 2 & 134 \\
\hline 5 & $\nu_{\mathrm{as}}(\mathrm{CH})_{\mathrm{ph} 1}(99)$ & & 3213 & 3087 & 22 & 389 & 3216 & 3090 & 1 & 56 \\
\hline 6 & $\nu(\mathrm{CH})_{\mathrm{ph} 2}(95)$ & & 3213 & 3087 & 11 & 269 & 3213 & 3087 & 11 & 251 \\
\hline 7 & $\nu_{\mathrm{as}}(\mathrm{CH})_{\mathrm{ph} 2}(92)$ & & 3205 & 3079 & 22 & 27 & 3205 & 3079 & 21 & 27 \\
\hline 8 & $\nu_{\mathrm{as}}(\mathrm{CH})_{\mathrm{ph} 1}(84)$ & & 3202 & 3076 & 11 & 189 & - & - & - & - \\
\hline 9 & $\nu_{\mathrm{as}}(\mathrm{CH})_{\mathrm{ph} 2}(92)$ & & 3198 & 3073 & 13 & 78 & 3198 & 3073 & 12 & 79 \\
\hline 10 & $\nu_{\mathrm{as}}(\mathrm{CH})_{\mathrm{ph} 1}(89)$ & 3036 & 3194 & 3069 & 2 & 64 & - & - & - & - \\
\hline 11 & $\nu_{\mathrm{as}}(\mathrm{CH})_{\mathrm{ph} 2}(94)$ & 2924 & 3190 & 3065 & 1 & 98 & 3190 & 3065 & 1 & 95 \\
\hline 12 & $\nu_{\mathrm{as}}(\mathrm{CH})_{\mathrm{ph} 1}(96)$ & & - & - & - & - & 3186 & 3061 & 3 & 32 \\
\hline 13 & $\nu_{\mathrm{as}}(\mathrm{CH})_{\mathrm{ph} 2}(97)$ & & 3183 & 3058 & 1 & 23 & 3183 & 3058 & 1 & 21 \\
\hline 14 & $\nu_{\mathrm{as}}(\mathrm{CH})_{\mathrm{ph} 1}(98)$ & 2853 & 3179 & 3054 & 4 & 28 & - & - & - & - \\
\hline 15 & $\nu(\mathrm{C} \equiv \mathrm{N})(89), \nu_{\text {as }}(\mathrm{CC})_{\mathrm{pyr}}(11)$ & 2224 & 2341 & 2249 & 37 & 1431 & 2341 & 2249 & 37 & 1809 \\
\hline 16 & $\nu(\mathrm{C}=\mathrm{O})(84)$ & 1697 & 1785 & 1715 & 622 & 441 & 1786 & 1716 & 653 & 612 \\
\hline 17 & $\nu(\mathrm{C}=\mathrm{O})(67)$ & 1652 & 1755 & 1686 & 339 & 53 & 1756 & 1688 & 329 & 75 \\
\hline 18 & $\nu(\mathrm{CC})_{\mathrm{ph} 2}(50)$ & & 1659 & 1594 & 1 & 50 & 1659 & 1594 & 1 & 50 \\
\hline 19 & $\nu(\mathrm{CC})_{\mathrm{ph} 1}(49), \nu(\mathrm{NN})(10)$ & & 1655 & 1590 & 51 & 625 & 1644 & 1580 & 221 & 1065 \\
\hline 20 & $\nu_{\mathrm{as}}(\mathrm{CC})_{\mathrm{ph} 2}(55)$ & 1513 & 1635 & 1571 & 3 & 12 & 1635 & 1571 & 4 & 15 \\
\hline 21 & $\nu_{\mathrm{as}}(\mathrm{CC})_{\mathrm{ph} 1}(35)$ & & 1628 & 1564 & 14 & 683 & 1610 & 1547 & 45 & 3722 \\
\hline 22 & $\nu_{\mathrm{as}}(\mathrm{CC})_{\mathrm{ph} 1}(24), \delta(\mathrm{NH})(20), \nu(\mathrm{N}-\mathrm{N})(12)$ & & 1600 & 1537 & 267 & 2528 & 1594 & 1532 & 153 & 2189 \\
\hline 23 & $\nu(\mathrm{CC})_{\mathrm{pyr}}(48)$ & & 1559 & 1498 & 73 & 1433 & 1560 & 1499 & 83 & 2656 \\
\hline 24 & $\nu(\mathrm{CC})_{\mathrm{ph} 2}(15), \delta(\mathrm{CCH})_{\mathrm{ph} 2}(35)$ & & 1535 & 1475 & 217 & 982 & 1535 & 1475 & 217 & 1448 \\
\hline 25 & $\delta(\mathrm{CCH})_{\mathrm{ph} 1, \mathrm{ph} 2}(46)$ & & 1530 & 1470 & 1 & 939 & 1526 & 1466 & 1 & 1158 \\
\hline 26 & $\nu_{\mathrm{as}}(\mathrm{CC})_{\mathrm{pyr}}(19), \nu(\mathrm{N}=\mathrm{C})(15)$ & 1447 & 1514 & 1455 & 480 & 183 & 1512 & 1453 & 695 & 255 \\
\hline 27 & $\delta(\mathrm{CCH})_{\mathrm{ph} 1}(23)$ & & 1494 & 1435 & 56 & 86 & - & - & - & - \\
\hline 28 & $\delta(\mathrm{CCH})_{\mathrm{ph} 2}(52)$ & 1410 & 1484 & 1426 & 39 & 53 & 1484 & 1426 & 41 & 61 \\
\hline 29 & $\nu(\mathrm{CC})_{\mathrm{ph} 1}(41)$ & & - & - & - & - & 1453 & 1396 & 55 & 83 \\
\hline 30 & $\nu(\mathrm{CC})_{\mathrm{pyr}}(15), \nu(\mathrm{N}=\mathrm{C})(12)$ & 1395 & 1438 & 1382 & 316 & 256 & 1437 & 1381 & 338 & 523 \\
\hline 31 & $\nu(\mathrm{N}-\mathrm{N})(11), \nu(\mathrm{NC})(13), \delta(\mathrm{NH})$ & & 1405 & 1350 & 277 & 257 & 1406 & 1351 & 318 & 776 \\
\hline 32 & $\delta(\mathrm{NH})(51), \nu(\mathrm{N}-\mathrm{N})(17)$ & & 1399 & 1344 & 196 & 2097 & 1399 & 1344 & 152 & 3400 \\
\hline 33 & $\nu_{\mathrm{as}}(\mathrm{CCH})_{\mathrm{ph} 1}(29), \delta(\mathrm{N}-\mathrm{H})(46)$ & & 1370 & 1316 & 7 & 44 & - & - & - & - \\
\hline 34 & $\delta(\mathrm{CCH})_{\mathrm{ph} 2}(12), \delta(\mathrm{CCH})_{\mathrm{ph} 2}(59)$ & 1302 & 1361 & 1308 & 1 & 1 & 1361 & 1308 & 1 & 2 \\
\hline 35 & $\nu(\mathrm{CC})_{\mathrm{ph} 1}(41)$ & & 1346 & 1293 & 58 & 5 & 1341 & 1288 & 88 & 26 \\
\hline 36 & $\delta(\mathrm{CC})_{\mathrm{ph} 1}(25), \delta(\mathrm{CCH})_{\mathrm{ph} 1}(63)$ & & - & - & - & - & 1333 & 1281 & 3 & 47 \\
\hline 37 & $\delta(\mathrm{CC})_{\mathrm{ph} 2}(39)$ & & 1332 & 1280 & 1 & 146 & 1331 & 1279 & 4 & 233 \\
\hline 38 & $\delta(\mathrm{CC})_{\mathrm{ph} 1, \mathrm{ph} 2, \mathrm{pyr}}(12), \nu(\mathrm{N}=\mathrm{C})(12)$ & 1270 & 1317 & 1265 & 9 & 1550 & 1318 & 1266 & 7 & 2670 \\
\hline 39 & $\nu(\mathrm{N}=\mathrm{C})(29)$ & 1202 & 1264 & 1214 & 4 & 60 & 1265 & 1215 & 4 & 71 \\
\hline 40 & $\nu(\mathrm{NC})(15), \nu_{\mathrm{as}}(\mathrm{CC})_{\mathrm{pyr}}(11)$ & & 1245 & 1196 & 1 & 1280 & 1247 & 1198 & 2 & 1768 \\
\hline 41 & $\sigma(\mathrm{CH})_{\mathrm{ph} 2}(74)$ & 1164 & 1210 & 1163 & 1 & 6 & 1210 & 1163 & 1 & 6 \\
\hline 42 & $\sigma(\mathrm{CH})_{\mathrm{ph} 1}(61)$ & & 1206 & 1159 & 6 & 726 & 1205 & 1158 & 4 & 1622 \\
\hline 43 & $\sigma(\mathrm{CH})_{\mathrm{ph} 2}(37)$ & & 1190 & 1143 & 0 & 6 & 1190 & 1143 & 0 & 9 \\
\hline 44 & $\nu_{\mathrm{as}}(\mathrm{CC})_{\mathrm{pyr}}(10)$ & & 1161 & 1115 & 0 & 597 & 1162 & 1116 & 2 & 789 \\
\hline 45 & $\sigma(\mathrm{CH})_{\mathrm{ph} 1}(42)$ & & 1142 & 1097 & 24 & 31 & 1144 & 1099 & 7 & 192 \\
\hline 46 & $\sigma(\mathrm{CH})_{\mathrm{ph} 1}(11), \nu_{\mathrm{as}}(\mathrm{CC})_{\mathrm{pyr}}(39)$ & & - & - & - & - & 1141 & 1096 & 21 & 73 \\
\hline 47 & $\delta(\mathrm{CCH})_{\mathrm{ph} 2}(40), \nu(\mathrm{CC})_{\mathrm{pyr}}(34)$ & 1068 & 1110 & 1066 & 4 & 3 & 1110 & 1066 & 4 & 4 \\
\hline 48 & $\nu(\mathrm{CC})_{\mathrm{ph} 1}(54), \nu(\mathrm{BrC})(12)$ & & - & - & - & - & 1091 & 1048 & 104 & 391 \\
\hline 49 & $\nu(\mathrm{CC})_{\mathrm{ph} 2}(19), \delta(\mathrm{CCH})_{\mathrm{ph} 2}(20)$ & 1004 & 1056 & 1015 & 2 & 17 & 1056 & 1015 & 2 & 25 \\
\hline 50 & $\sigma(\mathrm{CCN})_{\mathrm{pyr}}(12)$ & & 1025 & 985 & 5 & 22 & 1024 & 984 & 2 & 48 \\
\hline 51 & $\beta(\mathrm{CCC})_{\mathrm{ph} 1}(75)$ & & 1017 & 977 & 2 & 24 & 1017 & 977 & 57 & 94 \\
\hline
\end{tabular}


Comparison of the experimental FT-IR wave numbers $\left[\mathrm{cm}^{-1}\right]$ for $(2)$ compound and theoretical

TABLE VI cont. harmonic wave numbers $\left[\mathrm{cm}^{-1}\right]$ for hydrazone tautomer of (1) and (2) by B3LYP/6-31G(d,p) method.

\begin{tabular}{|c|c|c|c|c|c|c|c|c|c|c|}
\hline \multirow[b]{2}{*}{$\nu$} & \multirow[b]{2}{*}{ Assignments $\left(\% \mathrm{PED}^{d}\right)$} & \multirow[b]{2}{*}{$\operatorname{Expt}^{a}$} & \multicolumn{3}{|c|}{ (1) } & \multicolumn{2}{|c|}{ Theoretical } & \multicolumn{3}{|c|}{$(2)$} \\
\hline & & & $\mathrm{A}^{b}$ & $\mathrm{~B}^{c}$ & IR int. & $\mathrm{R}$ act. & $\mathrm{A}^{b}$ & $\mathrm{~B}^{c}$ & IR Int. & $\mathrm{R}$ act. \\
\hline 52 & $\beta(\mathrm{CCC})_{\mathrm{ph} 2}(63)$ & & 1014 & 974 & 33 & 10 & 1016 & 977 & 4 & 26 \\
\hline 53 & $\gamma(\mathrm{HNC})(75)$ & & 1005 & 966 & 8 & 195 & 1006 & 967 & 40 & 209 \\
\hline 54 & $\tau(\mathrm{CCH})_{\mathrm{ph} 2}(72)$ & & 1001 & 962 & 0 & 1 & 1001 & 962 & 0 & 1 \\
\hline 55 & $\tau(\mathrm{C}-\mathrm{H})_{\mathrm{ph} 1}(85)$ & 942 & 978 & 940 & 1 & 7 & 990 & 951 & 0 & 5 \\
\hline 56 & $\tau(\mathrm{C}-\mathrm{H})_{\mathrm{ph} 2}(93)$ & & 971 & 933 & 0 & 0 & 972 & 934 & 0 & 0 \\
\hline 57 & $\tau(\mathrm{C}-\mathrm{H})_{\mathrm{ph} 1}(90)$ & & - & - & - & - & 970 & 932 & 1 & 12 \\
\hline 58 & $\tau(\mathrm{C}-\mathrm{H})_{\mathrm{ph} 2}(86)$ & & 931 & 895 & 2 & 4 & 931 & 895 & 4 & 3 \\
\hline 59 & br(ph2-pyr) (27) & & 890 & 855 & 12 & 5 & 890 & 855 & 25 & 7 \\
\hline 60 & $\operatorname{br}(\mathrm{ph} 1)(20)$ & 829 & 863 & 829 & 4 & 40 & 865 & 831 & 10 & 45 \\
\hline 61 & $\tau(\mathrm{CCH})_{\mathrm{ph} 2}(94)$ & & 856 & 822 & 1 & 5 & 857 & 823 & 0 & 5 \\
\hline 62 & $\omega(\mathrm{C}-\mathrm{H})_{\mathrm{ph} 1}(58)$ & & 841 & 808 & 1 & 31 & 854 & 821 & 26 & 7 \\
\hline 63 & $\omega(\mathrm{C}-\mathrm{H})_{\mathrm{ph} 1}(83)$ & & - & - & - & - & 825 & 793 & 13 & 52 \\
\hline 64 & $\omega(\mathrm{C}-\mathrm{H})_{\mathrm{ph} 2}(35), \gamma(\mathrm{CCC})_{\mathrm{pyr}, \mathrm{ph} 2}(31)$ & 742 & 784 & 753 & 29 & 5 & 779 & 748 & 21 & 1 \\
\hline 65 & $\gamma(\mathrm{OCC})_{\mathrm{pyr}}(69), \gamma(\mathrm{CCC})_{\mathrm{pyr}}(16)$ & & 765 & 735 & 32 & 6 & 765 & 735 & 27 & 7 \\
\hline 65 & $\gamma(\mathrm{OCC})_{\mathrm{pyr}}(62)$ & & 746 & 717 & 33 & 2 & 747 & 718 & 20 & 1 \\
\hline 66 & br(ph1) (33) & & 726 & 698 & 18 & 30 & 731 & 702 & 13 & 16 \\
\hline 67 & $\delta(\mathrm{CCC})_{\mathrm{pyr}}(36)$ & & - & - & - & - & 728 & 699 & 10 & 42 \\
\hline 68 & $\operatorname{br}(\mathrm{ph} 1)(34)$ & 695 & 721 & 693 & 21 & 3 & 721 & 693 & 21 & 9 \\
\hline 69 & $\tau(\mathrm{HNC})_{\mathrm{pyr}}(41)$ & & 714 & 686 & 32 & 6 & 715 & 687 & 37 & 8 \\
\hline 70 & $\tau(\mathrm{CCC})_{\mathrm{pyr}}(65)$ & & 707 & 679 & 16 & 7 & 707 & 679 & 16 & 9 \\
\hline 71 & br(ph1-ph2-pyr) (33) & & 696 & 669 & 19 & 4 & 680 & 653 & 11 & 3 \\
\hline 72 & $\operatorname{br}(\mathrm{ph} 2)(15), \nu(\mathrm{CC})_{\mathrm{pyr}}(10)$ & 636 & 649 & 624 & 9 & 5 & 650 & 625 & 13 & 8 \\
\hline 73 & $\tau(\mathrm{HNC})_{\mathrm{pyr}}(18), \sigma(\mathrm{CCC})(10)$ & & 635 & 610 & 7 & 6 & 648 & 623 & 13 & 13 \\
\hline 74 & $\sigma(\mathrm{CCC})_{\mathrm{ph} 1}(69)$ & & 625 & 601 & 1 & 15 & 641 & 616 & 1 & 30 \\
\hline 75 & $\tau(\mathrm{HNC})_{\mathrm{pyr}}(10), \sigma(\mathrm{CCC})_{\mathrm{ph} 2}(20)$ & & 624 & 600 & 2 & 3 & 623 & 599 & 2 & 3 \\
\hline 76 & $\nu(\mathrm{C}-\mathrm{Br})(12)$ & & - & - & - & - & 562 & 540 & 26 & 78 \\
\hline 77 & $\gamma(\mathrm{CCC})_{\mathrm{pyr}}(17), \tau(\mathrm{NCC})_{\mathrm{pyr}}(41)$ & 555 & 541 & 520 & 0 & 3 & 541 & 520 & 0 & 3 \\
\hline 78 & $\tau(\mathrm{CCC})_{\mathrm{ph} 1}(19), \tau(\mathrm{CCN})_{\mathrm{ph} 1}(10)$ & & 530 & 509 & 32 & 17 & 528 & 507 & 11 & 36 \\
\hline 79 & $\tau(\mathrm{CCC})_{\mathrm{ph} 2, \mathrm{pyr}}(35)$ & 508 & 520 & 500 & 3 & 2 & 520 & 500 & 0 & 8 \\
\hline 80 & $\sigma(\mathrm{CCN})_{\mathrm{ph} 1}(10)$ & & 502 & 482 & 11 & 4 & 506 & 486 & 4 & 5 \\
\hline 81 & $\sigma(\mathrm{CCN})_{\mathrm{ph} 1}(16), \sigma(\mathrm{OCN})_{\mathrm{pyr}}(25)$ & & 469 & 451 & 2 & 16 & 474 & 455 & 4 & 34 \\
\hline 82 & $\sigma(\mathrm{NCC})_{\mathrm{pyr}}(34), \sigma(\mathrm{OCN})_{\mathrm{pyr}}(10), \nu(\mathrm{CC})(13)$ & & 437 & 420 & 26 & 21 & 443 & 426 & 8 & 19 \\
\hline 83 & $\tau(\mathrm{CCH})_{\mathrm{ph} 1}(10), \tau(\mathrm{CCC})_{\mathrm{ph} 1}(56), \sigma(\mathrm{CCN})_{\mathrm{ph} 1}(10)$ & & 417 & 401 & 2 & 21 & 424 & 407 & 1 & 30 \\
\hline 84 & $\tau(\mathrm{CNN})_{\mathrm{pyr}}(15), \tau(\mathrm{CCC})_{\mathrm{ph} 2}(11)$ & & 411 & 395 & 2 & 2 & 414 & 398 & 2 & 4 \\
\hline 85 & $\tau(\mathrm{CNN})_{\mathrm{pyr}}(11), \tau(\mathrm{CCC})_{\mathrm{ph} 2}$ & & 402 & 386 & 5 & 14 & 406 & 390 & 1 & 8 \\
\hline 86 & $\sigma(\mathrm{CCC})_{\mathrm{pyr}}(17), \sigma(\mathrm{OCN})_{\mathrm{pyr}}(26)$ & & 380 & 365 & 20 & 3 & 381 & 366 & 17 & 9 \\
\hline 86 & $\nu(\mathrm{C}-\mathrm{Br})(24)$ & & - & - & - & - & 347 & 333 & 27 & 7 \\
\hline 87 & $\gamma(\mathrm{BrCC})(21), \tau(\mathrm{CCN})_{\mathrm{ph} 1}$ & & - & - & - & - & 343 & 330 & 23 & 154 \\
\hline 88 & $\sigma(\mathrm{BrCC})_{\mathrm{ph} 1}(19)$ & & 305 & 293 & 3 & 14 & 302 & 290 & 5 & 4 \\
\hline 89 & $\delta(\mathrm{CCC})_{\mathrm{ph} 1}, \tau\left(\mathrm{C}-\mathrm{H}_{\mathrm{ph} 2}, \tau(\mathrm{CCC})_{\mathrm{pyr}}\right.$ & & 296 & 284 & 2 & 44 & - & - & - & - \\
\hline 90 & $\nu(\mathrm{BrC})(10), \tau(\mathrm{CCC})_{\mathrm{ph} 2}(10)$ & & 289 & 278 & 3 & 44 & 288 & 278 & 6 & 7 \\
\hline 91 & $\gamma(\mathrm{CCC})_{\mathrm{pyr}}(16), \tau(\mathrm{NCC})_{\mathrm{pyr}}(24)$ & & 264 & 254 & 1 & 3 & 266 & 256 & 1 & 2 \\
\hline 92 & $\gamma(\mathrm{CNC})_{\mathrm{pyr}}(16), \sigma(\mathrm{CCC})_{\mathrm{ph} 1}(10)$ & & 241 & 232 & 1 & 0 & 257 & 247 & 2 & 12 \\
\hline 93 & $\sigma(\mathrm{BrCC})_{\mathrm{ph} 1}(14), \gamma(\mathrm{CNC})_{\mathrm{pyr}}(16)$ & & 218 & 209 & 3 & 9 & 245 & 235 & 0 & 18 \\
\hline 94 & $\sigma(\mathrm{BrCC})_{\mathrm{ph} 1}(23)$ & & 184 & 177 & 1 & 5 & 194 & 186 & 2 & 1 \\
\hline 95 & $\tau(\mathrm{CNC})_{\mathrm{pyr}}(50)$ & & 169 & 162 & 2 & 1 & 173 & 167 & 1 & 12 \\
\hline 96 & $\sigma(\mathrm{CCC})_{\mathrm{pyr}}(13), \sigma(\mathrm{NCC})_{\mathrm{pyr}}(11)$ & & - & - & - & - & 161 & 155 & 1 & 3 \\
\hline 97 & $\sigma(\mathrm{NCC})_{\mathrm{pyr}}(12), \sigma(\mathrm{CCC})_{\mathrm{pyr}}(12), \tau(\mathrm{CNN})_{\mathrm{pyr}}(12)$ & & 139 & 134 & 3 & 16 & 154 & 148 & 3 & 10 \\
\hline
\end{tabular}

$\nu$ stretching vibrations; $\beta$ in-plane bending vibrations; $\gamma$ out-of-plane bending vibrations; $\omega$ wagging; $\tau$ twisting; $\sigma$ scissoring; $\delta$ rocking; br ring breath; s symmetric; as antisymmetric; pyr pyridone ring; ph benzene ring (the same below). ${ }^{a}$ Data are taken from Ref. [11], ${ }^{b}$ Unscaled wave number, ${ }^{c}$ Scaled by a factor of $0.9608,{ }^{d}$ PED less than $10 \%$ are not shown. 
hyperpolarizabilities (in a.u. and esu) using B3LYP/6$31 \mathrm{G}(\mathrm{d}, \mathrm{p})$ method. This study reveals that (1) and (2) compounds have large first-order hyperpolarizabilities and have the potential applications in the development of NLO materials. The FT-IR spectra of hydrazone forms of (1) and (2) molecules have been satisfactorily interpreted in terms of hydrogen bonded hydrazone tautomer.

\section{References}

[1] H. Çetişli, M. Karakuş, E. Erdem, H. Deligöz, J. Incl. Phenom. Macro. 42, 187 (2002).

[2] C.S. Wang, H.S. Fei, Y. Qiu, Y.Q. Yang, Z.Q. Wei, Y.Q. Tian, Y.M. Chen, Y.Y. Zhao, Appl. Phys. Lett. 74, 19 (1999).

[3] H. Zollinger, Colour Chemistry, VCH, Weinheim 1987.

[4] C.C. Chen, I.J. Wang, Dyes Pigm. 15, 69 (1991).

[5] W. Huang, H. Qian, Dyes Pigm. 77, 446 (2008).

[6] W. Huang, Dyes Pigm. 79, 69 (2008).

[7] C. Lubai, C. Xing, G. Kunyu, H. Jiezhen, J. Griffiths, Dyes Pigm. 7, 373 (1986).

[8] A. Cee, B. Horáková, A. Lyčka, Dyes Pigm. 9, 357 (1988).

[9] G.S. Ušćumlić, D.Z. Mijin, N.V. Valentić, V.V. Vajs, B.M. Sušić, Chem. Phys. Lett. 397, 148 (2004).

[10] Industrial Dyes: Chemistry, Properties, Applications, Ed. K. Hunger, Wiley-VCH, 2003.

[11] A. Alimmari, D. Mijin, R. Vukićević, B. Božić, N. Valentić, V. Vitnik, Ž. Vitnik, G. Ušćumlić, Chem. Cent. J. 6, 71 (2012).

[12] M.J. Frisch, G.W. Trucks, H.B. Schlegal, G.E. Scuseria, M.A. Robb, J.R. Cheesman, V.G. Zakrzewski, J.A. Jr. Mortgomerg, R.E. Stratmann, J.C. Burant, S. Dapprich, J.M. Millam, A.D. Daniels, K.N. Kudin, M.C. Strain, O. Farkas, J. Tomasi, V. Barone, M. Cossi, R. Cammi, J. Mennucci, G.A. Petersson, P.Y. Ayala, Q. Cui, K. Morokuma, N. Rega, P. Salvador, J.J. Dannenberg, D.K. Malich, A.D. Rabuck, K. Raghavachari, J.B. Foresman, J. Cioslowski, J.V. Ortiz, A.G. Baboul, B.B. Stetanov, G. Liu, A. Liashenko, P. Piskorz, J. Komaromi, R. Gomperts, R.L. Martin, D.J. Fox, T. Keith, M.A. Al. Laham, C.Y. Peng, A. Nanayakkara, M. Challacombe, P.M.W. Gill, B. Johnson, W. Chenp, M.W. Wong, J.L. Andres, C. Gonzalez, M. Head-Gordon, E.S. Replogle, J.A. Pople, Gaussian 09, Revision A.1, Gaussian Inc., Wallingford (CT) 2009.

[13] M.J. Frisch, G.W. Trucks, H.B. Schlegel, GaussView, Ver. 5.0.9, Semichem. Inc., Shawnee Mission (KS) 2009.

[14] A.D. Becke, J. Chem. Phys. 98, 5648 (1993).

[15] C. Lee, W. Yang, R.G. Parr, Phys. Rev. B 37, 785 (1988).

[16] M.H. Jamroz, VEDA \& Program, Warsaw 2004.

[17] A.P. Scott, L. Radom, J. Phys. Chem. 100, 16502 (1996).

[18] J.B. Foresman, A. Frisch, Exploring Chemistry with Electronic Structure Methods, Gaussian Inc., Pittsburgh 1996.
[19] E.D. Glendening, C.R. Landis, F. Weinhold, Comput. Mol. Sci. 2, 1 (2011).

[20] T.C. Koopmans, Physica (Amsterdam) 1, 104 (1933).

[21] P. Senet, Chem. Phys. Lett. 275, 527 (1997).

[22] L. Pauling, The Nature of the Chemical Bond, Cornell University Press, Ithaca 1960.

[23] A. Hinchliffe, B. Nikolaidi, H.J.S. Machado, Int. J. Mol. Sci. 5, 224 (2004).

[24] A.D. Buckingham, Adv. Chem. Phys. 12, 107 (1967).

[25] A.D. Mclean, M. Yoshimine, J. Chem. Phys. 47, 1927 (1967).

[26] C. Lin, K. Wu, Chem. Phys. Lett. 321, 83 (2000).

[27] J.P. Abraham, D. Sajan, I.J. Hubert, V.S. Jayakumar, Spectrochim. Acta A 71, 355 (2008).

[28] P. Karamanis, C. Pouchan, G. Maroulis, Phys. Rev. A 77, 013201 (2008).

[29] A. Ben Ahmed, H. Feki, Y. Abid, H. Boughzala, A. Mlayah, J. Mol. Struct. 888, 180 (2008).

[30] A. Streitwieser Jr., Molecular Orbital Theory for Organic Chemists, Wiley, New York 1961.

[31] K. Fukui, Science 218, 747 (1982).

[32] J. Dostanić, D. Mijin, G. Ušćumlić, D.M. Jovanović, M. Zlatar, D. Lončarević, Spectrochim. Acta A $\mathbf{1 2 3}$ 37 (2014).

[33] J. Mirković, J. Rogan, D. Poleti, V. Vitnik, Ž. Vitnik, G. Ušćumlić, D. Mijin, Dyes Pigments 104, 160 (2014).

[34] A. Esme, S.G. Sagdinc, J. Mol. Struct. 1048, 185 (2013).

[35] A. Temel, S. Ozbey, N. Ertan, Dyes Pigm. 32, 237 (1996).

[36] L.C. Abbott, S.N. Batchelor, J. Oakes, B.C. Gilbert, A.C. Whitwood, J.R.L. Smith, J.N. Moore, J. Phys. Chem. A 109, 2894 (2005).

[37] M.R. Almeida, R. Stephani, H.F. Dos Santos, L.F.C. De Oliveira, J. Phys. Chem. A 114, 526 (2010).

[38] V. Bertolasi, L. Nanni, P. Gilli, V. Ferreti, G. Gilli, New J. Chem. 18, 251 (1994).

[39] F.H. Allen, O. Kennard, D. Watson, L. Brammer, A.G. Orpen, R. Taylor, J. Chem. Soc. 2, S1 (1987).

[40] D.B. Pendergrass, I.C. Paul, D.Y. Curtin, J. Am. Chem. Soc. 94, 8730 (1972).

[41] P.K. Chattaraj, S. Nath, B. Maiti, Computational Medicinal Chemistry for Drug Discovery, Marcel Dekker, New York 2003.

[42] R.G. Parr, W. Yang, Density Functional Theory of Atoms and Molecules, Oxford University Press, Oxford 1989.

[43] P. Politzer, J. Murray, Theor. Chem. Acc. 108, 134 (2002).

[44] P. Politzer, J.S. Murray, Theoretical Biochemistry and Molecular Biophysics: A Comprehensive Survey, Adenine Press, New York 1991.

[45] O. Prasad, L. Sinha, N. Kumar, J. At. Mol. Sci. 1, 201 (2010).

[46] Y.G. Sidir, I. Sidir, J. Sci. Technol. 1, 7 (2011). 
[47] F. Weinhold, C.R. Landis, Chem. Educ. Res. Pract. Eur. 2, 91 (2001).

[48] M. Kaur, Y.S. Mary, H.T. Varghese, C.Y. Panicker, H.S. Yathirajan, M.S. Siddegowda, C. Van Alsenoy, Spectrochim. Acta Part A Mol. Biomol. Spectrosc. 98, 91 (2012).

[49] Y. Matsuda, T. Ebata, N. Mikami, J. Chem. Phys. 110, 8397 (1999).

[50] G. Varsanyi, Assignment for Vibrational Spectra of Seven Hundred Benzene Derivatives, Academic Kiaclo, Budapest 1973.

[51] M. Jag, Organic Spectroscopy-Principles and Applications, Narosa Publ. House, New Delhi 2001.
[52] M. Snehalatha, C. Ravikumar, I.J. Hubert, Solid State Sci. 11, 1275 (2009).

[53] J.B. Labbert, H.F. Shurvel, L. Verbit, R.G. Cooks, G.H. Stout, Organic Structural Analysis, Macmillan Publ. Co. Inc., New York 1976.

[54] H.P. Gümüs, O. Tamer, D. Avci, Y. Atalay, Spectrochim. Acta Part A Mol. Biomol. Spectrosc. 132, 183 (2014)

[55] A.J. LaPlante, H.D. Stidham, Spectrochim. Acta A 74, 808 (2009).

[56] W. Zierkiewicz, D. Michalska, T.H. ZeegersHuyskens, J. Phys. Chem. A 104, 11685 (2000). 